\title{
Hierarchically Porous Zeolite X Composites for Manganese Ion-exchange and Solidification: Equilibrium Isotherms, Kinetic and Thermodynamic Studies
}

DOI:

10.1016/j.cej.2016.09.081

\section{Document Version}

Accepted author manuscript

Link to publication record in Manchester Research Explorer

Citation for published version (APA):

Al-Jubouri, S., \& Holmes, S. (2017). Hierarchically Porous Zeolite X Composites for Manganese lon-exchange and Solidification: Equilibrium Isotherms, Kinetic and Thermodynamic Studies. Chemical Engineering Journal, 308. https://doi.org/10.1016/j.cej.2016.09.081

Published in:

Chemical Engineering Journal

\section{Citing this paper}

Please note that where the full-text provided on Manchester Research Explorer is the Author Accepted Manuscript or Proof version this may differ from the final Published version. If citing, it is advised that you check and use the publisher's definitive version.

\section{General rights}

Copyright and moral rights for the publications made accessible in the Research Explorer are retained by the authors and/or other copyright owners and it is a condition of accessing publications that users recognise and abide by the legal requirements associated with these rights.

\section{Takedown policy}

If you believe that this document breaches copyright please refer to the University of Manchester's Takedown Procedures [http://man.ac.uk/04Y6Bo] or contact uml.scholarlycommunications@manchester.ac.uk providing relevant details, so we can investigate your claim.

\section{OPEN ACCESS}


Hierarchically Porous Zeolite X Composites for Manganese Ion-exchange and Solidification: Equilibrium Isotherms, Kinetic and Thermodynamic Studies

Sama M. Al-Jubouri ${ }^{\mathrm{a}}$ and Stuart M. Holmes ${ }^{\mathrm{a}^{*}}$

${ }^{a}$ School of Chemical Engineering and Analytical Science, The University of Manchester, Manchester, M13 9PL, UK.

*stuart.holmes@manchester.ac.uk

\section{Abstract}

This paper deals with the kinetic and isotherm studies of manganese ion removal by zeolite $\mathrm{X}$ and its hierarchically porous composites as ion-exchange materials. A hydrothermal treatment was applied to grow a layer of zeolite $\mathrm{X}$ over diatomite and carbon surfaces. The hierarchically porous composites used for $\mathrm{Mn}^{2+}$ ion removal showed higher ion-exchange capacity when compared to pure zeolite $\mathrm{X}$ under same conditions. A thermodynamic study of the rate of ion-exchange revealed that the intra-particle diffusion rate constant of zeolite $\mathrm{X} /$ carbon and zeolite $\mathrm{X} /$ diatomite was higher than that of pure zeolite $\mathrm{X}$ indicating that the intra-particle diffusion was enhanced when zeolite was prepared in form of hierarchically porous composites. The study showed that the thickness of boundary film of zeolite X/carbon and zeolite $\mathrm{X} /$ diatomite was less than that of pure zeolite $\mathrm{X}$ indicating ion diffusion resistance to the active sites was reduced when the composites were utilised. The experimental data showed good agreement with Freundlich model. The calculated thermodynamic parameters such as $\Delta \mathrm{G}^{\circ}, \Delta \mathrm{H}^{\circ}$ and $\Delta \mathrm{S}^{\circ}$ indicated the ion-exchange process of $\mathrm{Mn}^{2+}$ ion by zeolite $\mathrm{X}$ and its composites was spontaneous, endothermic and the randomness increased at the liquid/solid interface under the conditions studied. The results of kinetic study showed that the ion-exchange of $\mathrm{Mn}^{2+}$ ion by zeolite $\mathrm{X}$ and its composites followed a pseudo second order 
kinetic model indicating $\mathrm{Mn}^{2+}$ ion removal is a chemical reaction related to valence forces. The encapsulation of $\mathrm{Mn}^{2+}$ ion was successfully achieved by vitrification and geopolymerization processes demonstrating the efficacy of both processes for environmental management.

Keywords: Hierarchical composites, Ion-exchange, Manganese, Solidification, Intra-particle diffusion, Kinetics.

\section{Introduction}

Zeolites are microporous aluminosilicate crystalline minerals with exchangeable cations having important functions as adsorbents, ion-exchangers or catalysts in many chemical and petrochemical industries and water treatment applications [1,2]. This important role is due to zeolite's unique properties of high surface area, uniform porosity, shape selectivity, high ionexchange capacity, strong Brønsted acidity and high (hydro)thermal stability. However, utilization of powdered zeolites for the industrial applications is often limited because of diffusion and access problems arising from the small zeolites pore size ranging of $0.3-1 \mathrm{~nm}$ which is similar to the dimensions of molecules $[3,4]$. The poor diffusion of relatively large reactant molecules or ions to the active sites present in the zeolite micropores may lead to the underutilization of the available zeolite internal surface area and volume, frequent blocking of the diffusion path and rapid zeolites deactivation [3,5]. The catalysis and uptake activity of zeolite is related to both the length of diffusion path and the diffusion coefficient. A shorter diffusion path length increases the diffusion coefficient and thus creates higher intrinsic zeolite activity [6]. To cope with drawbacks resulting from zeolite microporosity, great efforts have been dedicated to reduce the intracrystalline diffusion path length by preparing zeolites with a hierarchically porous structure $[4,7]$. Hierarchically porous zeolite can reduce 
or eliminate the undesired diffusion limitations of the reaction rate by offering shorter diffusion paths for reactant and product molecules inside the pores [8].

Hierarchical structure zeolite advantages come from the presence of micropores and mesopores/macropores [4]. With hierarchical zeolites, the meso- or macropores facilitate the access of bulky reactant molecules to the zeolite active sites in the micropores [3]. Hierarchical zeolites can be obtained by preparing mesoporous zeolites by post-synthesis modification (dealumination, desilication [9]) or removing a template which is introduced during synthesis $[4,10,11]$ or by preparing hierarchical zeolite composites [12]. Making the hierarchical zeolite composite materials is an effective approach because it does not require complicated steps relative to other synthesis routes. The key focus of this approach is finding a cheap and available porous support and achieving a homogeneous and permanent zeolite crystals coating the support surface.

Hierarchical zeolite composites are commonly prepared using a hydrothermal treatment to grow a zeolite layer onto a porous support [9,13-16]; or using a layer by layer approach which involves coating the support with zeolite crystals which have been previously prepared [17-19]. In the case of growing zeolite crystals on a porous support, it is important to generate nucleation sites on the porous support before mixing with zeolite gel and crystallization. Many types of porous support have been used to generate zeolite composites such as alumina [20,21], steel [22,23], carbon [13,19], polymers [24] and diatomite [9,25]. Porous carbons can be obtained from thermal treatment of available natural waste rich in carbon. Diatomite, diatomaceous earth or kieselguhr, is a low-density unicellular algae consisting of amorphous hydrated silica [9]. Diatomite has interesting properties of inherent macroporous structure, abundance and comparatively inexpensiveness [18]. The optimum performance of zeolites for different applications can be achieved by tailoring hierarchical 
zeolite structures with inexpensive porous supports targeting the pore architecture required for the process..

Generally zeolites are effective adsorbents or ion-exchangers in wastewater treatment across a range of contaminants [26]. Zeolites with low Si/Al ratio such as $\mathrm{NaA}$ and $\mathrm{NaX}$ zeolites are used to remove heavy metals from water by ion-exchange process. Their high affinity for ion-exchange is derived from high concentration of exchangeable non-framework cations available in their microporous structure [27].

Removing pollutants from the wastewaters of different industries is important because of the extremely damaging impact of many pollutants on the environment and public health [28]. Heavy metals are highly toxic and non-biodegradable and they can lead to severe diseases of nervous system and cancer [29]. Heavy metals are released with industrial effluents from different industries such as metal finishing, battery manufacture, metal plating, paints and pigments manufacture, mining, fertilizer production and rubber processing [30,31]. Manganese is one of the heavy metals discharged to the environment from the industries making dry battery cells, fertilizers, colorant for bricks, animal feed and electrical coils; also it results from the burning of coal and oil $[32,33]$.

According to the World Health Organisation, the daily nutritional requirement of manganese is $30-50 \mu \mathrm{g} / \mathrm{kg}$ and the allowable concentration in the drinking water is $0.5 \mathrm{mg} / \mathrm{l}$. Excessive concentrations of manganese are harmful to human health. The presence of manganese in water (even at concentrations lower than $0.5 \mathrm{mg} / \mathrm{l}$ ) causes black staining of food, laundering problems, objectionable stains to sanitaryware and impart a metallic taste. Also, exposure to manganese can cause neurological disorders and liver, kidney and lung damage $[30,34]$. When the manganese concentration exceeds the legal concentration in the 
water, it can cause hallucinations, nerve damage, lung embolism, bronchitis, schizophrenia, permanent disability, paralysis and tumours $[35,36]$.

Different technologies have been used to treat wastewater such as adsorption, electro floatation, evaporation, precipitation, coagulation, reverse osmosis, membrane separation, ion-exchange and liquid extraction [28,37,38]. However, most of these treatments are expensive, generate waste sludge and are not efficient in treating low concentrations of contaminants. Adsorption and ion-exchange approaches are the simplest and most effective methods to remove harmful elements. The effectiveness of these techniques depends on the efficiency of the adsorbent or/and ion-exchanger in uptaking the pollutant. Adsorbents can be activated carbon, biomaterials, clay minerals, zeolites or solid wastes resulting from some industries [26]. The ion-exchange process is a reversible ion-exchange reaction which happens when the ion-exchanger solid is equilibrated with an electrolyte solution having similar charge ions. Commercial ion-exchangers generally contain zeolites or resins.

Ion-exchange efficiently removes ions but it results in a harmful solid which when disposed of can lead to escaping of ions back into the environment. Therefore, solidification/stabilization technology has been widely used to treat contaminated solid waste because it has the merits of high resistance to biodegradation, ease of use, and it is comparatively inexpensive and stable [39]. Encapsulation of the harmful components inside a solid material can be conducted either by vitrification or geopolymerization.

Vitrification involves trapping inorganic wastes at elevated temperatures in a silicate melt provided by glass-forming materials. Vitrification generates solid materials possessing outstanding long-term chemical stability, the possibility of immobilizing relatively large amounts of heavy metal ions and a significant reduction of the waste volume [40,41]. Geopolymerization has been used to immobilize toxic metals due to the containment of the 
structure of the ion-exchanger by the geopolymer on solidification[42]. The geopolymerization process involves a rapid chemical reaction at ambient or slightly higher temperature under alkaline conditions to activate the $\mathrm{Si}$ and $\mathrm{Al}$ minerals and results in a three dimensional polymeric chain and ring structure consisting of Si-O-Al-O bonds $[43,44]$.

This study investigates the performance of hierarchical zeolite $\mathrm{X}$ composites in the removal of manganese ion from aqueous solution by ion-exchange process in comparison with pure zeolites $X$. Different parameters were investigated to explore the ion-exchange behaviour for the removal of manganese ions involving: contact time, initial ion concentration, $\mathrm{pH}$ of solution and temperature of solution. In addition, the equilibrium isotherm models, ion-exchange kinetics and thermodynamic parameters were comprehensively investigated to understand the behaviour and mechanism of the process. Finally, encapsulation of manganese ion was explored by vitrification and geopolymerization.

\section{Methodology}

\subsection{Preparation of ion-exchange materials}

Zeolite X was prepared based on the standard published synthesis [45-47]. The formula of zeolite $\mathrm{X}$ gel used for this work is [47]: $3.9 \mathrm{Na}_{2} \mathrm{O}: 1 \mathrm{Al}_{2} \mathrm{O}_{3}: 3 \mathrm{SiO}_{2}: 156 \mathrm{H}_{2} \mathrm{O}$, this was prepared by dissolving $0.99 \mathrm{~g}$ of $\mathrm{NaOH}(\mathrm{NaOH}$ pellets $99.9 \% \mathrm{wt}$, Fisher Scientific) in $20 \mathrm{~g}$ of deionised water to provide an alkali medium to carry out the reaction. After that, $1.55 \mathrm{~g}$ of sodium aluminate (anhydrous sodium aluminate 55-56\%wt $\mathrm{Al}_{2} \mathrm{O}_{3}$, Riedel-deHaën) was added to the $\mathrm{NaOH}$ solution with vigorous mixing. Once the solution became clear, $5.78 \mathrm{~g}$ of sodium silicate solution (10.6\%wt $\mathrm{Na}_{2} \mathrm{O}$ and $26.5 \%$ wt $\mathrm{SiO}_{2}$, Sigma-Aldrich) was added and mixed gently until a cream coloured gel was formed. Aging of the produced gel was performed overnight at room temperature. The gel was then put in a Teflon-lined autoclave and heated to $100^{\circ} \mathrm{C}$ for $6 \mathrm{~h}$. When the crystallization time was over, the product was filtered, washed 
with deionized water until the $\mathrm{pH}$ of the water was below 9 and then dried overnight at 70$80^{\circ} \mathrm{C}$. After that, the sample was collected and characterized by XRD, SEM, EDAX and Nitrogen adsorption/desorption isotherms.

Hierarchically porous zeolite X composite over diatomite and carbon were prepared hydrothermally by adding porous supports to the aluminosilicates gel. Diatomite (filter agent Celatom FW-80) used in this study was provided by Aldrich. The carbonaceous support was obtained by thermal treatment of Iraqi date stones. The collected date stones were washed, dried and the heated to $900^{\circ} \mathrm{C}$ for $3 \mathrm{~h}$ in a tubular furnace under flowing $\mathrm{N}_{2}$ gas. A suspension solution of zeolite $\mathrm{X}$ nanoparticles was prepared using ball milling. Zeolite $\mathrm{X}$ which was prepared previously was mixed with water and grinding media in the following proportions: 2 $\mathrm{H}_{2} \mathrm{O}$ : 1 zeolite $\mathrm{X}$ : 1 grinding media (0.3-0.4 mm diameter glass beads) and put in a plastic bottle with $5 \mathrm{~cm}$ diameter. The mixture was then allowed to rotate at a grinding speed 160 $190 \mathrm{rpm}$ for $32 \mathrm{~h}$. The resultant suspension was collected and allowed to settle for 2 days to separate large particles from the suspension. The resulting suspension was used later for the synthesis process of composite zeolite.

Before adding the porous support to the zeolite gel, both diatomite and carbon were exposed to ultrasonication for $6 \mathrm{~h}$ in the presence of a suspension of zeolite $\mathrm{X}$ nanoparticles (support: suspension nanoparticles weight ratio was 15:1 [14]). After ultrasonication, diatomite and carbon were filtered, washed and dried overnight at $50-70^{\circ} \mathrm{C}$. A weight of support equal to five times weight of silica present in the silica source was added to the aged gel and mixed for 15 minutes. After that, the resultant mixture were put in Teflon-lined autoclaves and heated in an oven at $100^{\circ} \mathrm{C}$. The crystallization time of the composite materials was increased to avoid partially crystallized products. Therefore, zeolite $\mathrm{X} /$ diatomite sample was crystallized for $24 \mathrm{~h}$. While, zeolite X/carbon sample was crystallized for $8 \mathrm{~h}$. After that, the produced composites were filtered, washed, dried and 
characterized by XRD, SEM, EDAX, Nitrogen adsorption/desorption isotherms and TGA (for zeolite $\mathrm{X} /$ carbon composite).

\subsection{Ion-exchange experiments}

A study of manganese ion removal by zeolite $\mathrm{X}$, composite zeolite $\mathrm{X} /$ carbon and zeolite $\mathrm{X} /$ diatomite was performed in batch reactors under continuous stirring. Manganese nitrate tetrahydrate (purity of $\geq 97 \%$, Sigma-Aldrich) was utilized to prepare $\mathrm{Mn}^{2+}$ ion solutions. To study the effect of contact time and identify the equilibrium time, $0.2 \mathrm{~g}$ of ion-exchange material was left in contact with $100 \mathrm{ml}$ of solution (300 ppm initial ion concentration) under mixing for $24 \mathrm{~h}$. To investigate the efficacy of the ion-exchange materials, different doses of media of $0.2,0.5,0.8$ and $1 \mathrm{~g}$ was added to $100 \mathrm{ml}$ of $300 \mathrm{ppm}$ ions solution. For the effect of initial ion concentration and ion-exchange isotherm studies, a series of $125 \mathrm{ml}$ tubes was used, each tube containing a fixed weight of ion-exchange material $(0.2 \mathrm{~g})$ was filled with $100 \mathrm{ml}$ of ion solution (50-700 ppm) and shaken for $4 \mathrm{~h}$ at room temperature. The manganese solutions were colourless. The thermodynamic studies and temperature effect on the ionexchange process were performed at different temperatures of 12,30 and $50^{\circ} \mathrm{C}$ (weight of ion-exchangers of $0.2 \mathrm{~g}$, the initial ion concentration of $300 \mathrm{ppm}$ and solution volume of 100 ml). All these studies were conducted at a $\mathrm{pH}$ which was given by the initial ion concentration without modification. However to study the effect of the $\mathrm{pH}$ of the solution on the performance of ion-exchange materials, the $\mathrm{pH}$ of the solutions were changed using $\mathrm{HCl}$ (conc. 31.5-33\%, BDH laboratory) and $\mathrm{NaOH}(\mathrm{NaOH}$ pellets 99.9\%wt, Fisher Scientific). 0.2 $\mathrm{g}$ of carbon support was added to $100 \mathrm{ml}$ of $300 \mathrm{ppm}$ manganese solution to check whether carbon give an ion-exchange capacity for $\mathrm{Mn}^{2+}$ ion.

For each run and before adding the ion-exchange materials, $1 \mathrm{ml}$ of the solution present in each tube was taken to measure the initial ion concentration. After which, samples 
were taken periodically every $1 \mathrm{~h}$ to determine the remaining concentration of manganese in the solution by ICP-OES.

\subsection{Solidification of the spent zeolite}

The solidification of the ion-exchange materials containing manganese ions was performed by vitrification and geopolymer. Geopolymers used for this study were made of two different raw materials namely kaolin and fly ash. Leaching of manganese ion from the solidified products was evaluated using $\mathrm{NaCl}$ solution and $\mathrm{H}_{2} \mathrm{SO}_{4}$ solution.

\subsubsection{Vitrification}

Encapsulation of manganese ions (manganese boiling point of $2061^{\circ} \mathrm{C}$ ) was carried out by heating the used ion-exchange materials up to $1200^{\circ} \mathrm{C}$ (heating rate $5^{\circ} \mathrm{C}$ ) for $2 \mathrm{~h}$ at which temperature the zeolite turns to glass a product. The sample weight of the spent materials was measured before and after thermal treatment. The produced solids were then left in contact with $30 \mathrm{ml}$ of deionized water and $30 \mathrm{ml}$ of $0.1 \mathrm{M} \mathrm{NaCl}$ solution. The concentration of manganese ion leached to solutions was measured by ICP-OES after 1 month and 6 months. $0.1 \mathrm{M} \mathrm{NaCl}$ solution was prepared from sodium chloride (99.5\%, BDH laboratory). $\mathrm{NaCl}$ was used in this study because it is strong in the striping of ions from ion-exchangers.

\subsubsection{Geopolymerization}

The geopolymers were prepared according to standard literature procedures $[44,48,49]$ using alkaline solution to activate the geopolymer raw materials. The geopolymer raw materials used here were kaolin (WBB minerals, UK origin) and fly ash (Cemex, 450-S). The elemental analysis of both kaolin and fly-ash given by EDAX analysis is shown in Table 1. Solidification by geopolymers was accomplished by mixing $2.5 \mathrm{ml}$ of $\mathrm{NaOH}$ solution $(10 \mathrm{M})$ with $0.5 \mathrm{ml}$ of sodium silicate solution for $15 \mathrm{~min}$ to obtain an activator solution. A 
homogeneous mixture of $0.25 \mathrm{~g}$ of manganese-bearing materials and $2.5 \mathrm{~g}$ of kaolin was obtained by hand-mixing for $10 \mathrm{~min} .5 \mathrm{~g}$ of fly ash was mixed with $0.25 \mathrm{~g}$ of manganesebearing materials when fly ash was used to prepare the geopolymer. $2 \mathrm{~g}$ of both raw materials were used in the case geopolymer prepared with this ratio 50\% kaolin:50\% fly ash. The solid mixture was mixed with $2.5 \mathrm{ml}$ of the activator solution for $15 \mathrm{~min}$ at room temperature and then poured into a cast mould.

The curing process of samples was performed at $70^{\circ} \mathrm{C}$ for $24 \mathrm{~h}$ followed by 7 days at room temperature. After that, the resulting samples were left in contact with water, $0.1 \mathrm{M}$ $\mathrm{NaCl}$ solution and $0.25 \mathrm{M} \mathrm{H}_{2} \mathrm{SO}_{4}$ solution. $0.25 \mathrm{M} \mathrm{H}_{2} \mathrm{SO}_{4}$ solution was prepared from sulfuric acid (96\%, ACROS Organics). ICP-OES was used to measure the concentration of manganese leached to the solution after 1 month and 6 months of contact time.

Table 1: The elemental analysis of kaolin and fly ash according to EDAX.

\begin{tabular}{|c|c|c|c|c|c|c|c|c|c|c|c|}
\hline Element & $\begin{array}{c}\mathbf{C} \\
(\mathbf{W t} \%)\end{array}$ & $\begin{array}{c}\mathbf{O} \\
(\mathbf{W t} \%)\end{array}$ & $\begin{array}{c}\mathbf{N a} \\
(\mathbf{W t} \%)\end{array}$ & $\begin{array}{c}\mathbf{M g} \\
(\mathbf{W t} \%)\end{array}$ & $\begin{array}{c}\mathbf{A l} \\
(\mathbf{W t} \%)\end{array}$ & $\begin{array}{c}\mathbf{S i} \\
(\mathbf{W t} \%)\end{array}$ & $\begin{array}{c}\mathbf{S} \\
(\mathbf{W t} \%)\end{array}$ & $\begin{array}{c}\mathbf{K} \\
(\mathbf{W t} \%)\end{array}$ & $\begin{array}{c}\mathbf{C a} \\
(\mathbf{W t} \%)\end{array}$ & $\begin{array}{c}\mathbf{T i} \\
(\mathbf{W t} \%)\end{array}$ & $\begin{array}{c}\mathbf{F e} \\
(\mathbf{W t} \%)\end{array}$ \\
\hline Kaolin & 32.57 & 27.46 & 0.07 & 0.28 & 16.96 & 20.01 & 0.17 & 1.33 & 0.19 & 0.15 & 0.80 \\
\hline Fly ash & 30.78 & 22.80 & 0.89 & 0.75 & 13.07 & 17.13 & 0.35 & 2.21 & 3.46 & 0.73 & 7.84 \\
\hline
\end{tabular}

\subsection{Analytical techniques}

The characterization for zeolite and composite samples by XRD was performed on a Miniflex Rigaku X-ray analytical instrument with $\mathrm{CuK} \alpha$ radiation source $(\lambda=1.5418 \AA)$, voltage $=30$ $\mathrm{kV}$, current $=30 \mathrm{~mA}$, scan speed $=3^{\circ} \mathrm{min}^{-1}$, step size $=0.03,2 \theta=5-45^{\circ}$ and total time $\sim 20$ min. The scanning electron microscopy (SEM) and energy dispersive analysis by X-ray (EDAX) were conducted using model FEI Quanta 200. To conduct the SEM imaging, the samples were coated with gold by a sputter coater. While, EDAX analysis was carried out without coating the samples. The Thermo Gravimetric analyser (TGA, model Q5000IR TA 
Instruments Company) was used to determine the percentage of zeolite in zeolite/carbon composite. The sample was heated to $900^{\circ} \mathrm{C}$ at a rate of $10^{\circ} \mathrm{C} / \mathrm{min}$ under air atmosphere.

Inductively Coupled Plasma-Optical Emission Spectroscopy (ICP-OES, model VistaMPX by Varian) was used to obtain manganese concentration in the samples resulting from ion-exchange and solidification experiments.

Nitrogen adsorption/desorption isotherms at $-196^{\circ} \mathrm{C}$ were obtained using a Micrometrics ASAP 2020. Surface area was determined using the Brunauer-Emmett-Teller method (BET method). The degassing was carried out at $200^{\circ} \mathrm{C}$ for $10 \mathrm{~h}$ under vacuum prior to the measurement.

\section{Results and discussion}

\subsection{Characterization of zeolite and composites}

The XRD patterns of the prepared samples are shown in Figure 1 to demonstrate the structure and purity of the zeolite phase. Fully crystallized zeolite $X(X)$ was prepared by hydrothermal treatment. Hence, the XRD pattern of the prepared sample is identical to the commercial zeolite X. Also, both zeolite X/carbon (XC) and zeolite X/diatomite (XD) gave similar pattern to the pattern of pure form zeolite $\mathrm{X}$. The matching between composites pattern and pure form zeolite indicates that the presence of a solid porous support does not affect crystallization of the required phase or the phase purity. 


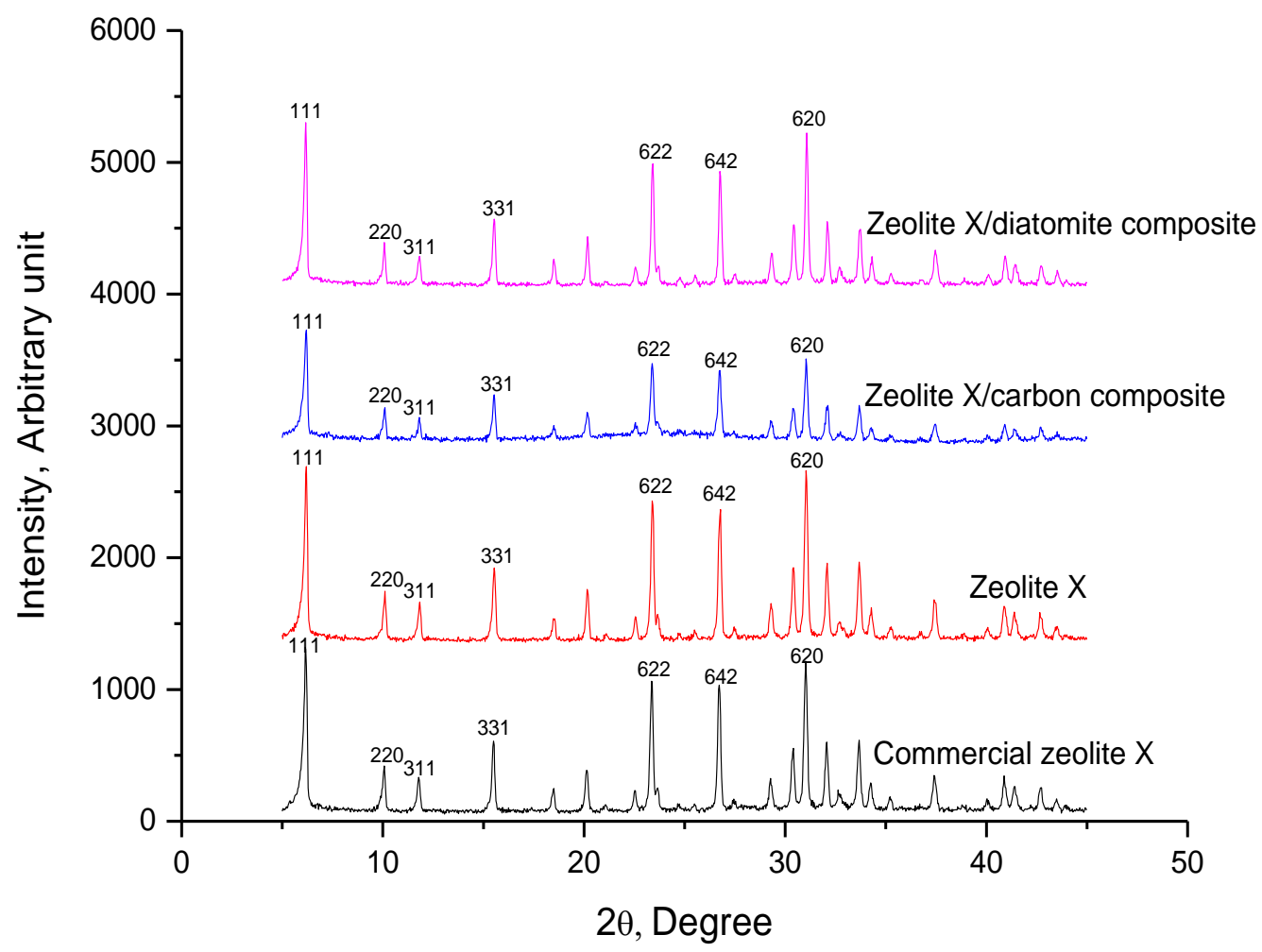

Figure 1: XRD pattern of commercial zeolite $\mathrm{X}$, synthesized zeolite $\mathrm{X}$, zeolite $\mathrm{X} /$ carbon composite and zeolite $\mathrm{X} /$ diatomite composite.

Figure $2 \mathrm{a}$ shows the SEM images of the porous carbon support produced by a thermal treatment of date stones. Figure $2 b$ shows SEM image of diatomite. The morphology of zeolite $\mathrm{X}$ and both zeolite composites are presented in Figure 3. Pure zeolite $\mathrm{X}$ was successfully crystallized from the mother gel under the conditions used for preparation (Figure 3a-1). Figure 3b-1 and Figure 3c-1 reveal zeolite coating on the support surfaces. These results confirm that hydrothermal treatment is effective method for preparing zeolite composites with uniform coating of fully crystallized crystals. The EDAX results are presented in Figure 3a-2, b-2 and c-2 and the percentage of each element consists zeolite and composites structure are presented in Table 2 and they indicate that the $\mathrm{Si} / \mathrm{Al}$ ratio was 1.35 for zeolite $\mathrm{X}$ and 1.4 for zeolite $\mathrm{X} /$ carbon composite. While, zeolite $\mathrm{X} /$ diatomite composite gave higher ratio than those because diatomite skeleton is formed of silica. During TGA analysis, the $\mathrm{X} /$ carbon composite was heated to $900^{\circ} \mathrm{C}$ in air atmosphere. The TGA results 
shown in Figure 4 give the percentage of zeolite $\mathrm{X}$ present in zeolite $\mathrm{X} /$ carbon composite is 23.91\%. The purpose of doing TGA for zeolite X/carbon composite is to obtain the percentage of zeolite $\mathrm{X}$ present in the zeolite X/carbon composite which is the responsible of the ion-exchange.
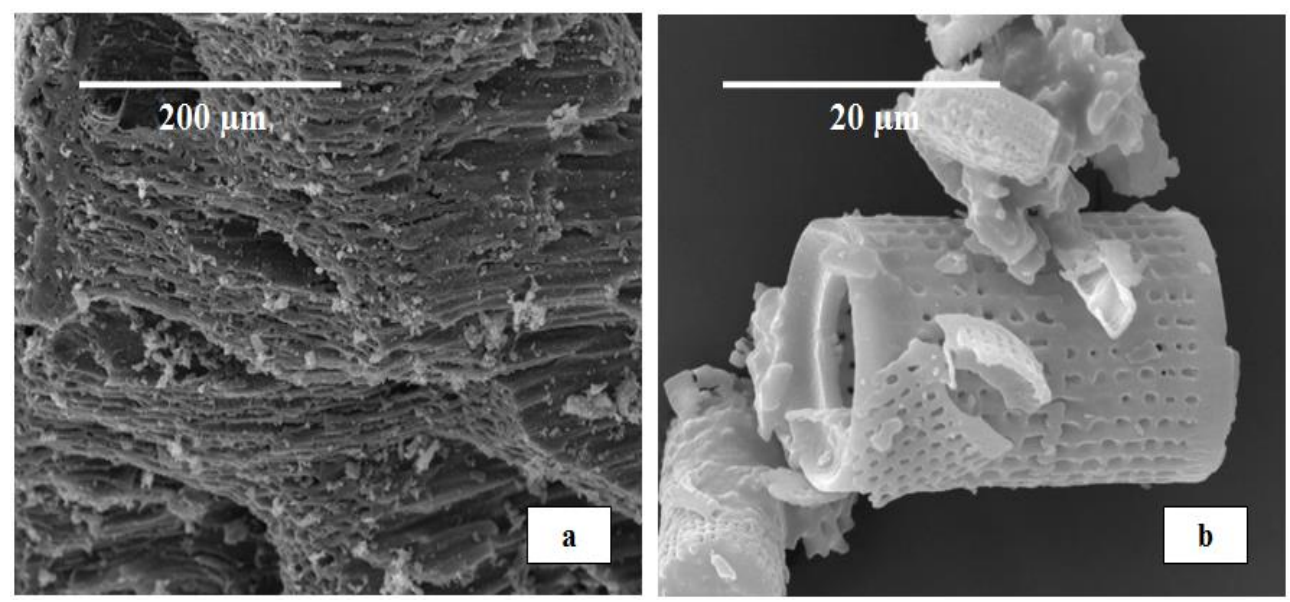

Figure 2: SEM images of porous supports (a) carbon and (b) diatomite. 


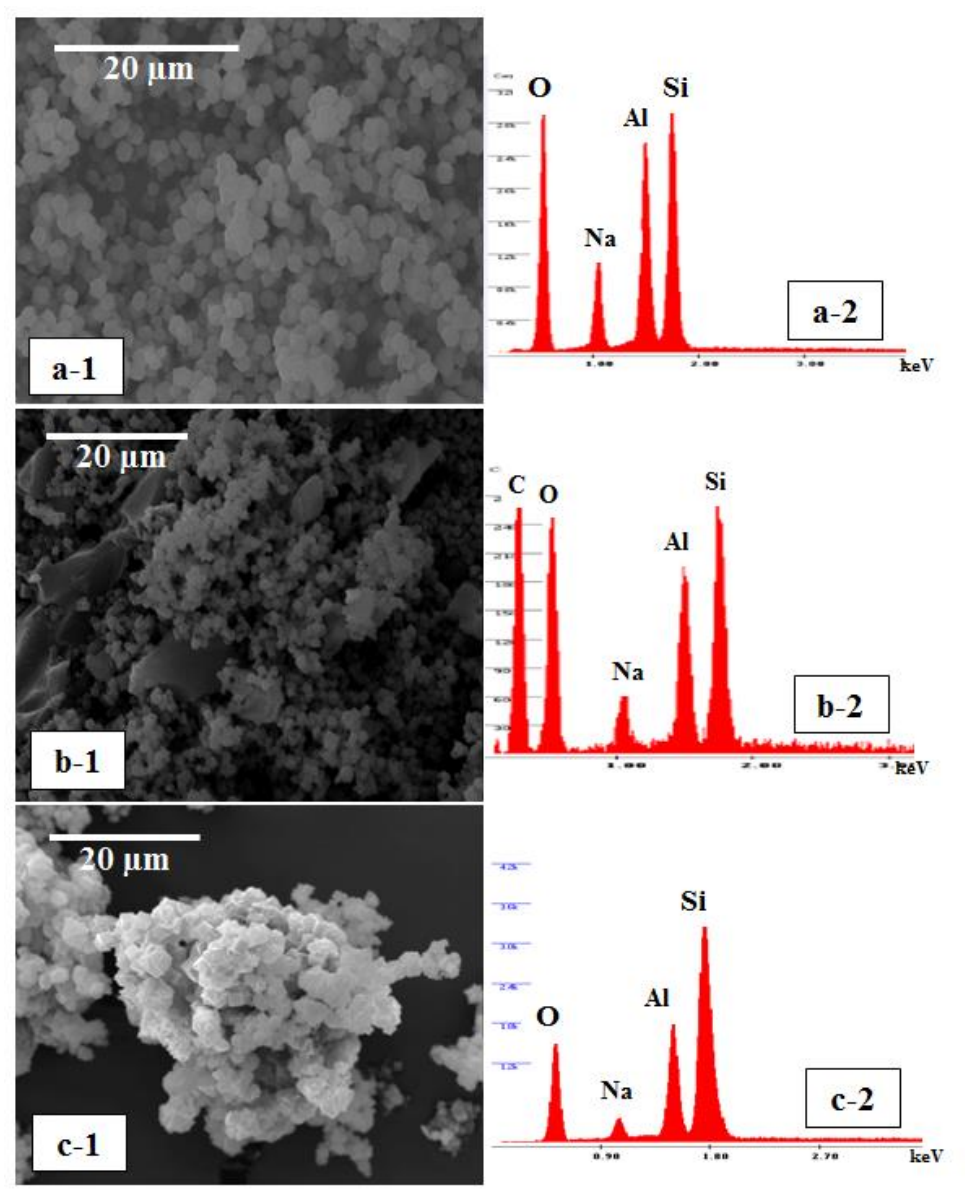

Figure 3: SEM image and EDAX results of (a) zeolite X, (b) zeolite X/carbon composite and (c) zeolite $\mathrm{X} /$ diatomite composite.

Table 2: The elemental analysis of zeolite $\mathrm{X}$, zeolite $\mathrm{X} /$ carbon composite and zeolite $\mathrm{X} /$ diatomite composite before ion-exchange according to EDAX.

\begin{tabular}{|c|c|c|c|}
\hline \multirow{2}{*}{ Element } & X & XC & XD \\
\cline { 2 - 4 } & Wt.\% & Wt.\% & Wt.\% \\
\hline O & 43.53 & 16.31 & 32.94 \\
\hline Na & 8.26 & 2.57 & 3.96 \\
\hline Al & 20.52 & 4.07 & 18.18 \\
\hline Si & 27.69 & 5.70 & 44.92 \\
\hline C & - & 71.35 & - \\
\hline Total & 100 & 100 & 100 \\
\hline
\end{tabular}




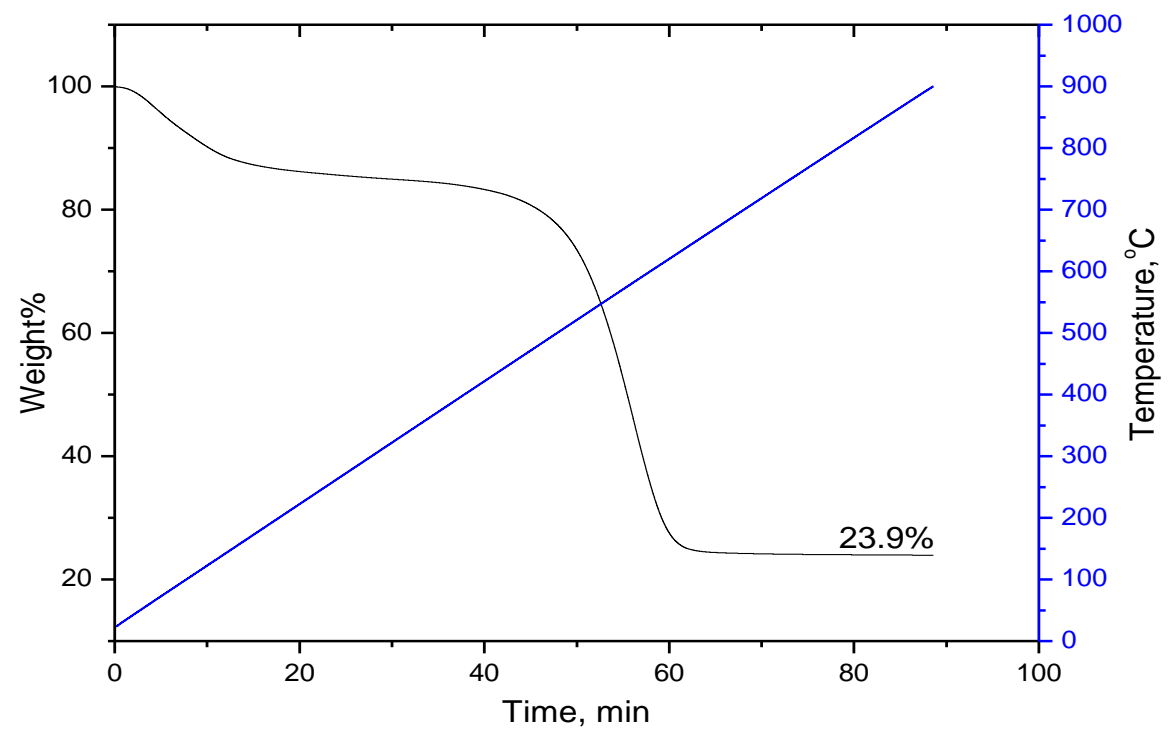

Figure 4: TGA result of zeolite X/carbon composite.

The structure properties such as BET surface area, pore volume and mesopore volume of zeolite $\mathrm{X}$ and zeolite $\mathrm{X}$ composites are shown in Table 3. The surface area and pore volume of zeolite X composites were lower $\left(168.288 \mathrm{~m}^{2} / \mathrm{g}\right.$ and $0.0756 \mathrm{~cm}^{3} / \mathrm{g}$ for XC, and $100.467 \mathrm{~m}^{2} / \mathrm{g}$ and $0.0856 \mathrm{~cm}^{3} / \mathrm{g}$ for XD) than those for zeolite $\mathrm{X}\left(656 \mathrm{~m}^{2} / \mathrm{g}\right.$ and $\left.0.3459 \mathrm{~cm}^{3} / \mathrm{g}\right)$ because low amounts of zeolite $\mathrm{X}$ coating on the support surface. The mesopore volume $\left(0.0258 \mathrm{~cm}^{3} / \mathrm{g}\right.$ for $\mathrm{XC}$ and $0.0644 \mathrm{~cm}^{3} / \mathrm{g}$ for XD) appeared in the composites samples due to introducing a mesoporosity within the composite structure. The percentage of zeolite $\mathrm{X}$ in the zeolite $\mathrm{X}$ /diatomite composite was obtained by estimating the micropores volume relative to the total pore volume and the percentage was $24.79 \%$.

Table 3: The structure properties of ion-exchange materials obtained from $\mathrm{N}_{2}$ adsorption/desorption isotherms.

\begin{tabular}{|c|c|c|c|}
\hline Ion-exchange materials & $\mathrm{S}_{\mathrm{BET}}\left(\mathrm{m}^{2} / \mathrm{g}\right)$ & $V_{\text {Total }}\left(\mathrm{cm}^{3} / \mathrm{g}\right)$ & $V_{\text {Mesopores }}\left(\mathrm{cm}^{3} / \mathrm{g}\right)$ \\
\hline $\mathbf{X}$ & $656.251 \pm 17.241$ & 0.3459 & - \\
\hline $\mathbf{X C}$ & $168.288 \pm 3.058$ & 0.0756 & 0.0258 \\
\hline XD & $100.467 \pm 0.808$ & 0.0856 & 0.0644 \\
\hline $\begin{array}{l}\mathrm{S}_{\mathrm{BET}}: \text { BET surface area. } \\
\mathrm{V}_{\text {Total }}: \text { Total pore volume. } \\
\mathrm{V}_{\text {Mesopores }} \text { : Volume of mes }\end{array}$ & ores. & & \\
\hline
\end{tabular}




\subsection{Manganese ion-exchange study}

The results will be presented in this section in form of ion-exchange capacity (q) which was calculated according to the following equation:

$$
\mathrm{q}=\left(\mathrm{C}_{\mathrm{o}}-\mathrm{C}_{\mathrm{t}}\right) * \mathrm{~V} / \mathrm{W}
$$

Equation 1

Where $\mathrm{q}(\mathrm{mg} / \mathrm{g})$ is the amount of ion exchanged per mass of ion-exchange material $\mathrm{W}(\mathrm{g}), \mathrm{V}$ (l) is the solution volume, $C_{o}$ and $C_{t}$ are the concentrations of ion in solution $(\mathrm{mg} / \mathrm{l})$ at $t=0$ and $\mathrm{t}=\mathrm{t}(\mathrm{h})$ respectively. At equilibrium time, $\mathrm{C}_{\mathrm{eq}}$ is the equilibrium ion concentration and $\mathrm{q}_{\mathrm{eq}}$ is the ion-exchange capacity at equilibrium.

\subsubsection{Effect of contact time}

Figure 5 shows the effect of contact time on $\mathrm{Mn}^{2+}$ ion removal from aqueous solutions. The carbon support prepared from date stones show no significant ion-exchange capacity when it was used to remove $\mathrm{Mn}^{2+}$ ion. Generally, $\mathrm{Mn}^{2+}$ ion uptake by the zeolitic materials used increased rapidly with increasing of the contact time, after that it increased gradually until reach to the equilibrium time. This is because, at the beginning, the ion-exchange sites on the zeolites surface, which contain exchangeable cations $\left(\mathrm{Na}^{+}\right)$, are not exchanged. But with time, those cations continue to exchange with the guest ions until reach to the equilibrium and the ion concentration in the solution becomes steady.

The ion-exchange capacity of the ion-exchange materials showed the following order: $\mathrm{X}>\mathrm{XD}>\mathrm{XC}$. Both $\mathrm{XC}$ and $\mathrm{XD}$ composites showed lower ion-exchange capacity than $\mathrm{X}$ because XC contains $23.91 \%$ zeolite X according to TGA results and XD contains $24.79 \%$ zeolite $\mathrm{X}$ according to BET method results. Therefore, the performance of composites for ion-exchange with manganese ion is due to this percentage of zeolite in the composites. The ion-exchange capacity calculated based on the real weight of zeolite used is in the order: XD 
$>\mathrm{XC}>\mathrm{X}$. The $\mathrm{pH}$ of manganese solutions before ion-exchange was $\sim 4.14$. But, it was ranging of 6.3-7.5 after ion-exchange due to changing ionic composition of the zeolite.

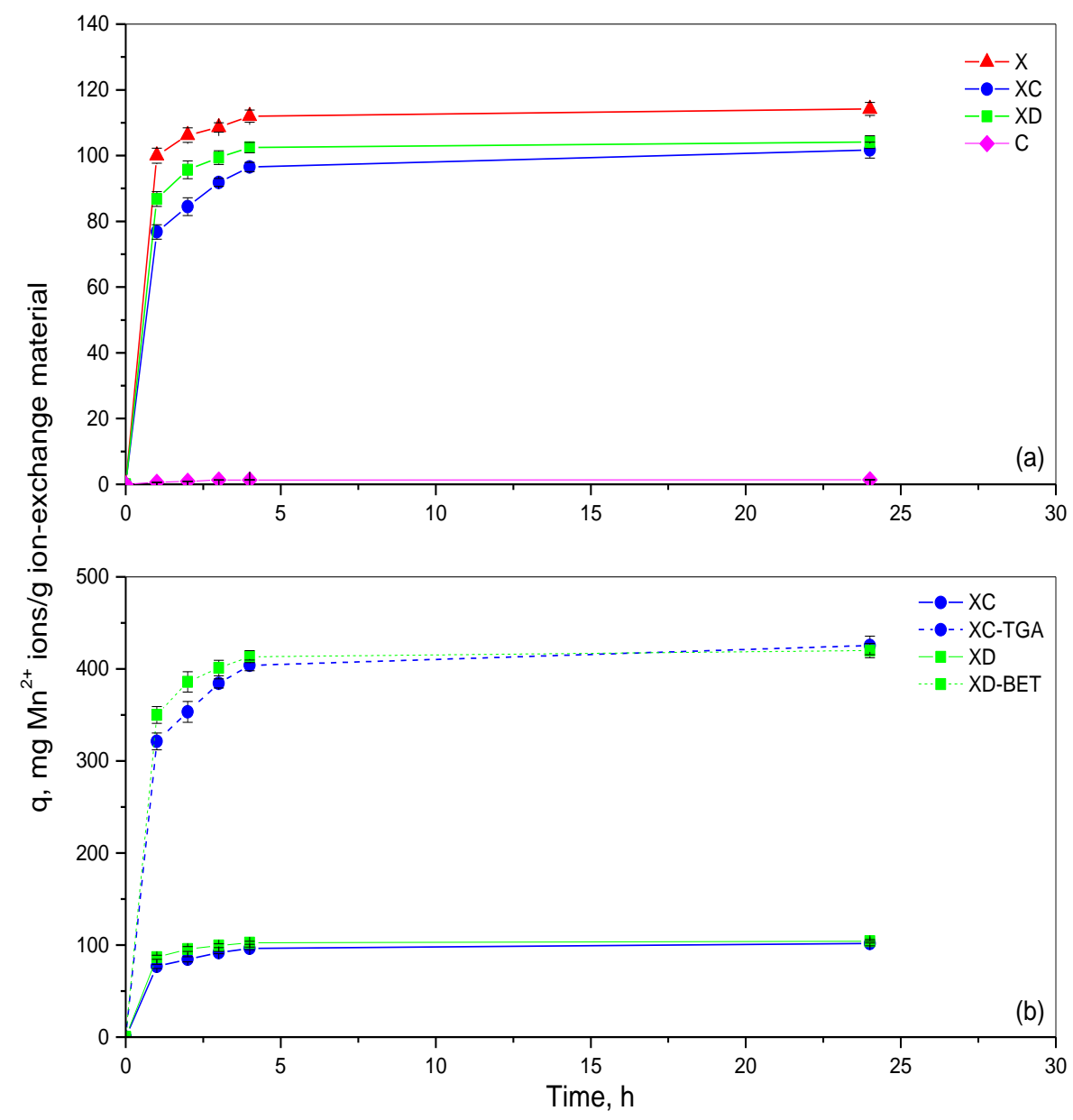

Figure 5: a) Study of the equilibrium time on the removal of manganese ion, b) a comparison based on the weight of zeolite. Ion initial concentration $=300 \mathrm{ppm}$, ion-exchange material dose $=2 \mathrm{~g}$, solution volume $=100$ $\mathrm{ml}, \mathrm{pH}=4$ and room temperature. TGA refers to the results obtained by TGA and BET refers to the results obtained by $\mathrm{N}_{2}$-adsorption/desorption isotherms (BET method).

Figure 6 shows the SEM images and EDAX results of ion-exchange materials after ion-exchange with $\mathrm{Mn}^{2+}$ ions. The SEM images of the composites materials revealed that mixing during ion-exchange process did not affect the attachment of zeolite crystals on the supports surface. EDAX results showed appearance of peaks relevant to manganese ion (as shown in inset figures) which indicate that the ion-exchange materials successfully take the 
$\mathrm{Mn}^{2+}$ ion out of solutions. The elemental analysis obtained by EDAX of X, XC and XD after ion-exchange is shown Table 4.
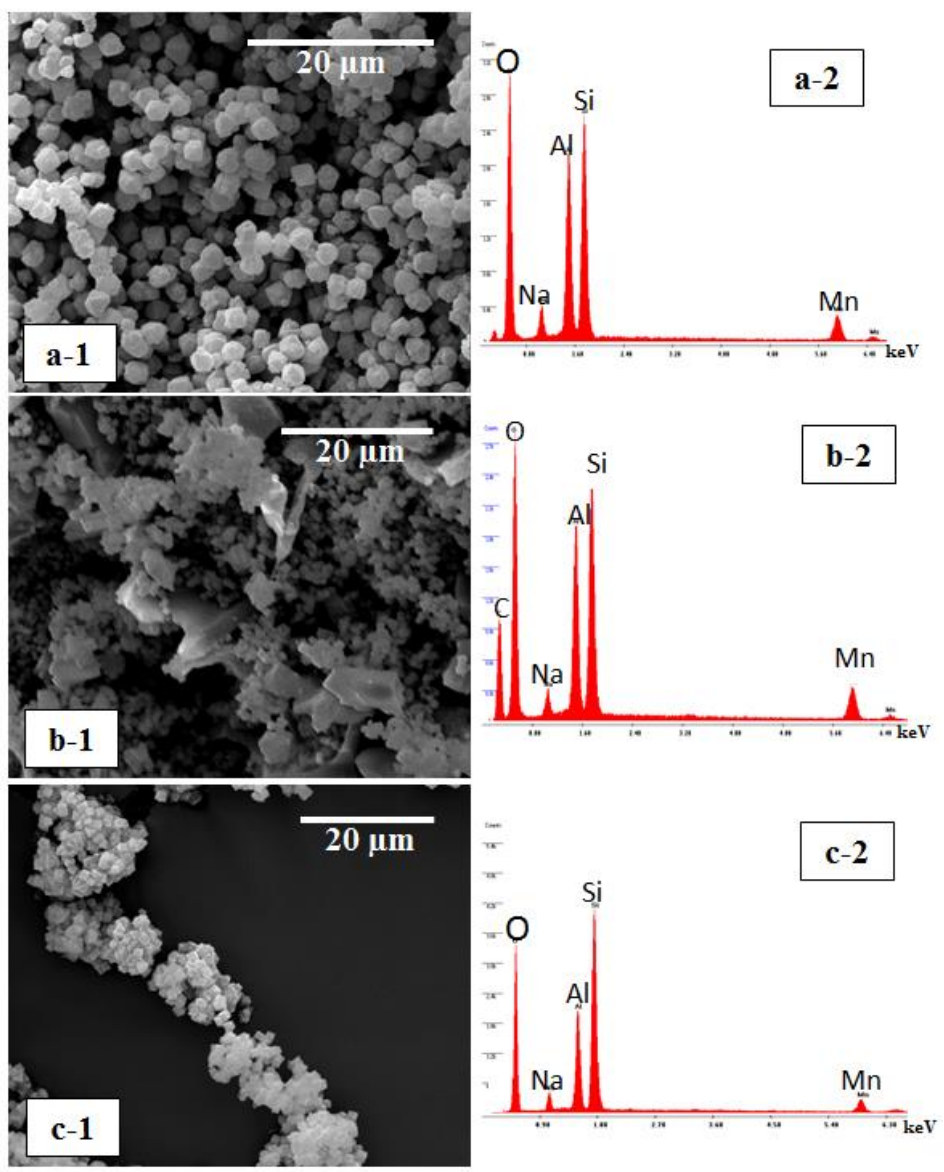

Figure 6: SEM and EDAX of ion-exchange materials after ion-exchange with $\mathrm{Mn}^{2+}$ ion. (a) zeolite $\mathrm{X}(\mathrm{X}),(\mathrm{b})$ zeolite X/carbon composite (XC) and zeolite X/diatomite composite (XD).

Table 4: The elemental analysis of zeolite $\mathrm{X}$, zeolite $\mathrm{X} /$ carbon composite and zeolite $\mathrm{X} /$ diatomite composite after ion-exchange according to EDAX.

\begin{tabular}{|c|c|c|c|}
\hline \multirow{2}{*}{ Element } & $\mathrm{X}$ & $\mathrm{XC}$ & $\mathrm{XD}$ \\
\cline { 2 - 4 } & $\mathrm{Wt} . \%$ & $\mathrm{Wt} \%$ & $\mathrm{Wt} . \%$ \\
\hline $\mathbf{O}$ & 45.58 & 43.55 & 43.12 \\
\hline $\mathbf{N a}$ & 4.47 & 3.68 & 3.31 \\
\hline $\mathbf{A l}$ & 17.54 & 10.45 & 13.94 \\
\hline $\mathbf{S i}$ & 23.77 & 14.87 & 32.80 \\
\hline $\mathbf{C}$ & - & 21.15 & - \\
\hline $\mathbf{M n}$ & 8.44 & 6.10 & 6.83 \\
\hline Total & 100 & 100 & 100 \\
\hline
\end{tabular}




\subsubsection{Initial ion concentration}

The influence of initial ion concentration on the ion-exchange process of $\mathrm{Mn}^{2+}$ ion is shown in Figure 7. It can be seen that the value of q gradually increased with increasing the initial manganese concentration. For a fixed weight of ion-exchange material, the amount of ions removed per gram of ion-exchange material increased with increasing the initial ion concentration. This is due to increasing the number of ions competing for the same number of ion-exchange sites present in a certain weight of ion-exchange material. Increasing initial manganese concentration leads to increase the concentration gradient which is the driving force for mass transfer and motivate the ion-exchange process.

The $\mathrm{pH}$ of manganese solutions was measured before ion-exchange process being conducted as shown in Table 5. It can be seen that the $\mathrm{pH}$ of manganese solutions decreases with increasing manganese concentration i.e. manganese solutions become more acidic at high manganese concentration. This fact explains why there is no sharp increasing in the $\mathrm{q}$ value with increasing the initial manganese concentration.

Table 5: The $\mathrm{pH}$ of manganese solutions with different initial manganese concentration.

\begin{tabular}{|c|c|c|c|c|c|c|c|c|}
\hline Concentration of manganese solution, ppm & $\mathbf{5 0}$ & $\mathbf{1 0 0}$ & $\mathbf{2 0 0}$ & $\mathbf{3 0 0}$ & $\mathbf{4 0 0}$ & $\mathbf{5 0 0}$ & $\mathbf{6 0 0}$ & $\mathbf{7 0 0}$ \\
\hline $\mathbf{p H}$ of the solution & 4.8 & 4.74 & 4.39 & 4.14 & 4.05 & 3.9 & 3.83 & 3.72 \\
\hline
\end{tabular}




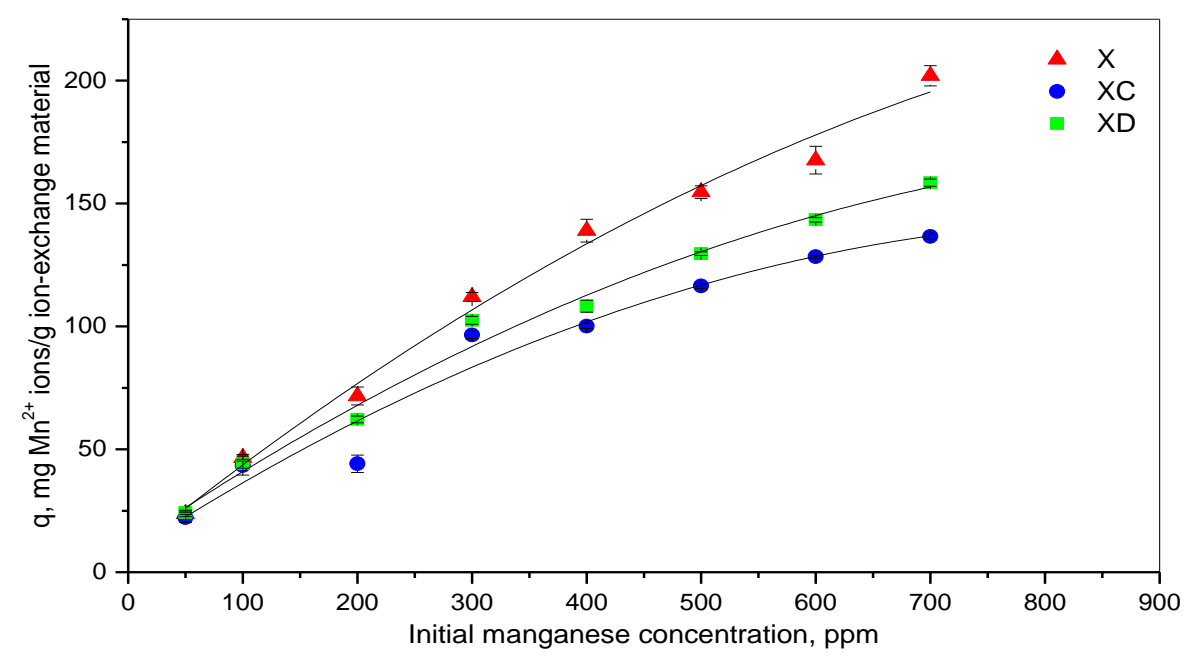

Figure 7: Effect of initial manganese concentration on ion-exchange process. Ion-exchange material weight $=2$ $\mathrm{g}$, solution volume $=100 \mathrm{ml}, \mathrm{t}=4 \mathrm{~h}$ and room temperature.

\subsubsection{Solution pH}

Figure 8 shows the ion-exchange capacity of ion-exchange materials against $\mathrm{pH}$ of manganese solution. The $\mathrm{pH}$ solution is an effective parameter on the ion-exchange process. This is because $\mathrm{pH}$ is linked to hydrogen ions which compete with metal ions for actives sites during ion-exchange process. Also, it affects the zeolites structure. The results shown in Figure 8 showed that of the amount of manganese ions exchanged per unit mass of ionexchange material increased with raising the $\mathrm{pH}$ of solution. This is because of reduction of the concentration of $\mathrm{H}^{+}$in the alkaline medium which competes with manganese ions for the zeolitic cations. Moreover, reducing of solution $\mathrm{pH}$ causing of collapse of zeolite structure and reduces the number of ion-exchange sites present within the zeolite structure. Where, a reduction in the peak height was noticed when XRD was conducted for the zeolitic materials used for experiment conducted at $\mathrm{pH}=2$. The $\mathrm{pH}$ of manganese solution cannot be increased more than $\sim 6.5$ because of manganese ion precipitation. 


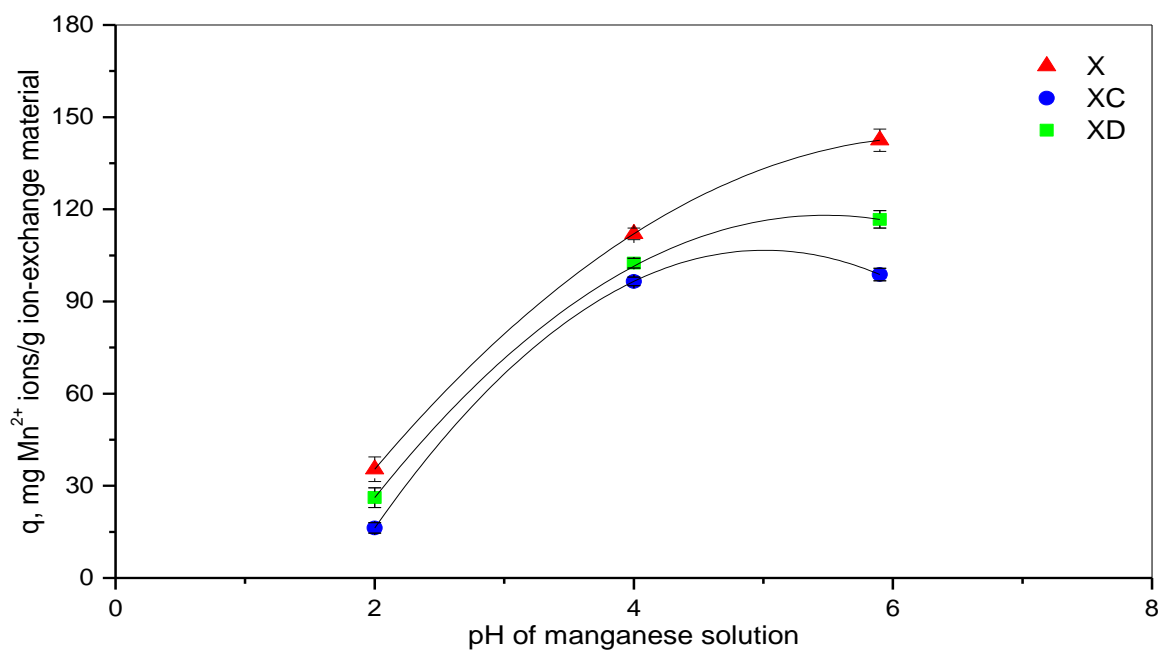

Figure 8: Effect of solution $\mathrm{pH}$ on the removal of manganese ion. Initial manganese concentration $=300 \mathrm{ppm}$, ion-exchanger dose $=2 \mathrm{~g}$, solution volume $=100 \mathrm{ml}, \mathrm{t}=4 \mathrm{~h}$ and room temperature.

\subsubsection{Temperature of solution}

The results describing the effect of temperature on the manganese ions removal from aqueous solution are shown in Figure 9. The amount of manganese ion removed per a certain mass of ion-exchange material increased with increasing temperature to $\sim 50^{\circ} \mathrm{C}$. This is because the rate of intra-particle diffusion of manganese ions is enhanced by increasing temperature of solution [50]. The diffusing species and the zeolite framework are electrically charged, therefore the rate of diffusion depends on temperature [51]. That means that ion-exchange process of manganese ion is an endothermic process. Temperature is related to the thermodynamic parameters namely free energy of ion-exchange $\left(\Delta \mathrm{G}^{\mathrm{o}}\right)$, enthalpy $\left(\Delta \mathrm{H}^{\mathrm{o}}\right)$ and entropy $\left(\Delta S^{o}\right)$. Thus, it is an important to investigate the influence of temperature on the ionexchange process. 


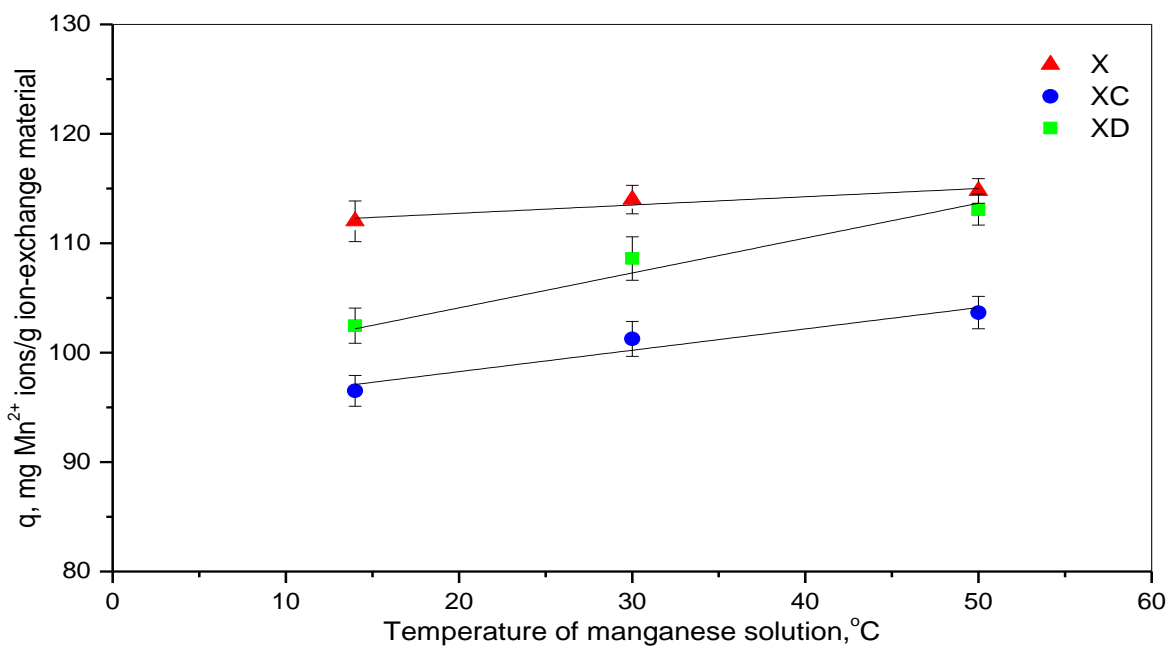

Figure 9: Effect of temperature on the removal of manganese ion. Initial manganese concentration $=300 \mathrm{ppm}$, ion-exchanger dose $=2 \mathrm{~g}$, solution volume $=100 \mathrm{ml}, \mathrm{pH}=4$ and $\mathrm{t}=4 \mathrm{~h}$.

Evaluating the free energy change $\left(\Delta \mathrm{G}^{\mathrm{o}}\right)$ determines the spontaneous behaviour of the ion-exchange process [31,52]. The endothermic nature of the ion-exchange process is determined by calculating the enthalpy of reaction $\left(\Delta \mathrm{H}^{\circ}\right)$. While, the randomness (degree of disorder resulting from exchanging of ions) at the solid/solution interface is determined by estimating the entropy $\left(\Delta S^{\circ}\right)[53]$. The thermodynamic parameters were calculated using the distribution coefficient $\left(\mathrm{K}_{\mathrm{d}} \mathrm{ml} / \mathrm{g}\right)$ expressed by Equation 2 at different temperature.

$$
\mathrm{K}_{\mathrm{d}}=\left(\mathrm{C}_{\mathrm{o}}-\mathrm{C}_{\mathrm{eq}}\right) * \mathrm{~V} /\left(\mathrm{W}^{*} \mathrm{C}_{\mathrm{eq}}\right) \quad \text { Equation 2 }
$$

The Gibbs free energy change of the ion-exchange process was calculated using Equation 3:

$$
\Delta \mathrm{G}^{\mathrm{o}}=-\mathrm{RT} \ln \mathrm{K}_{\mathrm{d}}
$$

Equation 3

The values of $\Delta \mathrm{G}^{\mathrm{o}}(\mathrm{kJ} / \mathrm{mol})$ were calculated at different temperatures using the values of the distribution coefficient $[30,53]$. The Gibbs free energy change is related to the enthalpy $\left(\Delta \mathrm{H}^{\circ}\right)$ and the entropy $\left(\Delta S^{\circ}\right)$ at any temperature using Equation 4:

$$
\Delta \mathrm{G}^{\mathrm{o}}=\Delta \mathrm{H}^{\mathrm{o}}-\mathrm{T} \Delta \mathrm{S}^{\mathrm{o}}
$$

Equation 4 
Thus, the values of enthalpy $\left(\Delta \mathrm{H}^{\circ}\right)$ and the entropy $\left(\Delta \mathrm{S}^{\circ}\right)$ can be calculated using the van't Hoff equation (Equation 5);

$$
\ln \mathrm{K}_{\mathrm{d}}=\Delta \mathrm{S}^{\mathrm{o}} / \mathrm{R}-\Delta \mathrm{H}^{\mathrm{o}} / \mathrm{RT}
$$

Equation 5

The values of $\Delta \mathrm{H}^{\mathrm{o}}(\mathrm{kJ} / \mathrm{mol})$ and $\Delta \mathrm{S}^{\mathrm{o}}(\mathrm{kJ} / \mathrm{mol} . \mathrm{K})$ were calculated by plotting of $\ln \mathrm{Kd}$ against 1/T [30,54-57]. Table 6 presents the results of $K_{d}$ and the thermodynamic parameters. The negative values of the Gibbs free energy increased with increasing temperature. This means that the ion-exchange process is spontaneous and the spontaneity of the ion-exchange process increases with increasing temperature which is thermodynamically favourable. The linear plots of $\ln \mathrm{K}_{\mathrm{d}}$ against $1 / \mathrm{T}$ to obtain $\Delta \mathrm{H}^{\circ}$ and $\Delta \mathrm{S}^{\circ}$ values are shown in Figure 10 and the results are shown in Table 6. The positive values of $\Delta \mathrm{H}^{\mathrm{o}}$ are attributed to the endothermic nature of the ion-exchange process of $\mathrm{Mn}^{2+}$ ion. The positive value of $\Delta \mathrm{S}^{\mathrm{o}}$ implies increasing of the randomness at the ion-exchanger/solution interface film during the ion-exchange of $\mathrm{Mn}^{2+}$ ion. Since, more of $\mathrm{Mn}^{2+}$ ions replace the zeolites cations leads to more randomness in the system.

Table 6: $\mathrm{K}_{\mathrm{d}}$ and thermodynamic parameters values obtained for $\mathrm{Mn}^{2+}$ ion-exchange.

\begin{tabular}{|c|c|c|c|c|c|}
\hline Ion-exchanger material & $\mathbf{T}(\mathbf{K})$ & $\mathrm{K}_{\mathrm{d}}(\mathrm{ml} / \mathrm{g})$ & $\Delta \mathbf{G}^{\mathbf{0}}(\mathrm{kJ} / \mathrm{mol})$ & $\Delta H^{0}(\mathrm{~kJ} / \mathrm{mol})$ & $\Delta S^{\mathbf{0}}(\mathrm{kJ} / \mathrm{mol} . \mathrm{K})$ \\
\hline \multirow[t]{3}{*}{$\mathbf{X}$} & 285 & 1474.076 & -60.657 & \multirow[t]{3}{*}{2.02} & \multirow[t]{3}{*}{0.068} \\
\hline & 303 & 1582.986 & -61.250 & & \\
\hline & 323 & 1629.744 & -61.492 & & \\
\hline \multirow[t]{3}{*}{$\mathbf{X C}$} & 285 & 902.2295 & -56.576 & \multirow[t]{3}{*}{4.33} & \multirow[t]{3}{*}{0.072} \\
\hline & 303 & 1038.916 & -57.749 & & \\
\hline & 323 & 1118.521 & -58.362 & & \\
\hline \multirow[t]{3}{*}{ XD } & 285 & 1044.736 & -57.795 & \multirow[t]{3}{*}{7.7} & \multirow[t]{3}{*}{0.085} \\
\hline & 303 & 1311.739 & -59.687 & & \\
\hline & 323 & 1530.919 & -60.972 & & \\
\hline
\end{tabular}



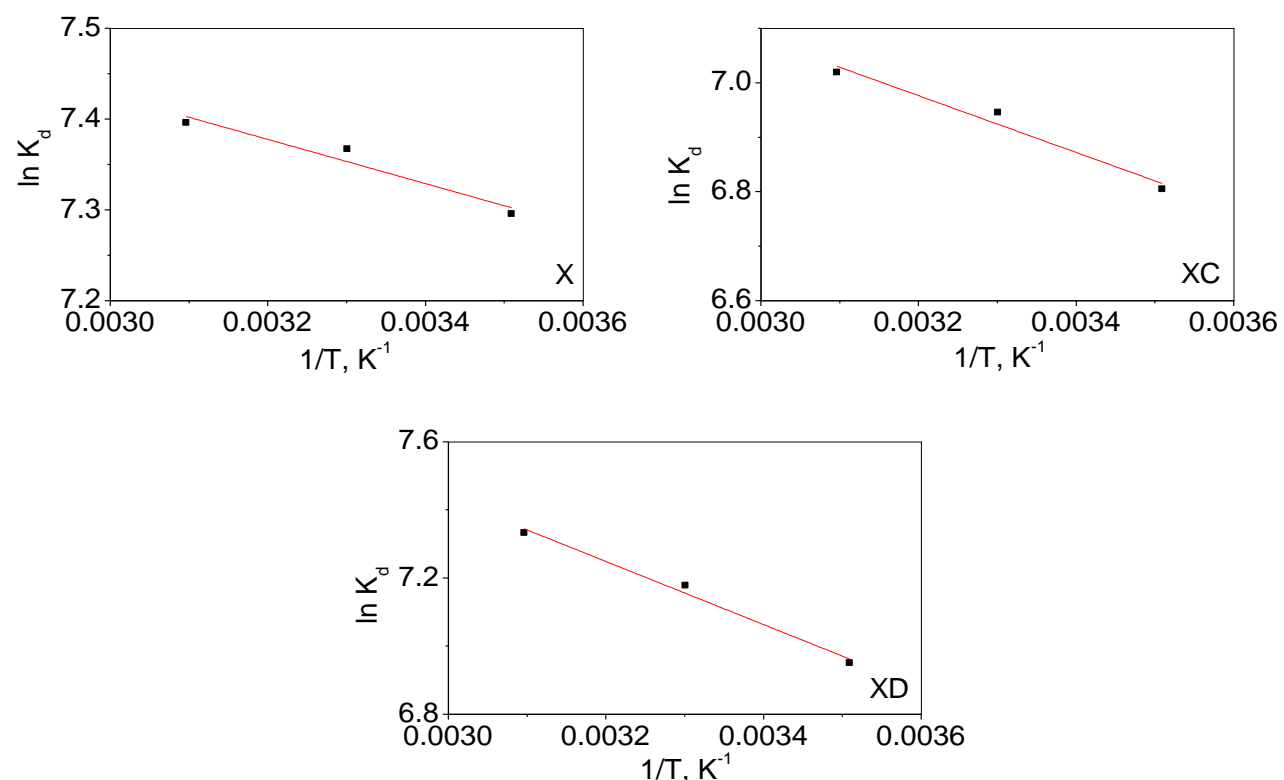

Figure 10: Van't Hoff plot for $\mathrm{Mn}^{2+}$ ion-exchange.

\subsection{Equilibrium isotherm models}

Conducting the equilibrium isotherm study is essential to calculate the maximum ionexchange capacity and to optimize the ion-exchange process design. Ion-exchange isotherm model generally relates the mass of ion-exchange material with equilibrium concentration of ions in the solution at constant temperature [31,53]. The experimental data were fitted with Langmuir isotherm model, Freundlich isotherm model and Dubinin- Radushkevich (D-R) isotherm model [50]. The correlation factor $\left(\mathrm{R}^{2}\right)$ was used to indicate the validity of the model to the experimental data. The highest value of $\mathrm{R}^{2}$ indicates a better fit of the model to the experimental data.

The Langmuir isotherm model assumes a monolayer coverage occurs at identical sites with homogeneous energy $[28,58,59]$. The linear form of Langmuir isotherm equation is expressed as [60]:

$$
\mathrm{q}_{\mathrm{eq}} / \mathrm{C}_{\mathrm{eq}}=\mathrm{q}_{\mathrm{m}} \mathrm{K}_{\mathrm{L}}-\mathrm{K}_{\mathrm{L}} \mathrm{q}_{\mathrm{eq}}
$$

Equation 6 
Where $\mathrm{q}_{\mathrm{eq}}(\mathrm{mg} / \mathrm{g})$ is the amount of ion removed per a unit mass of ion-exchange material, $\mathrm{C}_{\mathrm{eq}}$ $(\mathrm{mg} / \mathrm{l})$ is the equilibrium concentration of ion, $\mathrm{q}_{\mathrm{m}}(\mathrm{mg} / \mathrm{g})$ is Langmuir constant and it is the ultimate possible ion-exchange capacity and $\mathrm{K}_{\mathrm{L}}(1 / \mathrm{mg})$ is Langmuir constant representing the free energy of ion-exchange corresponds to the affinity between the ion and the surface of the ion-exchanger, respectively $[61,62]$. The values of $\mathrm{q}_{\mathrm{m}}$ and $\mathrm{K}_{\mathrm{L}}$ were obtained by plotting $\mathrm{q}_{\mathrm{eq}} / \mathrm{C}_{\mathrm{eq}}$ against $\mathrm{q}_{\mathrm{eq}}$, see Figure 11.

The Freundlich isotherm model assumes the uptake occurs at a multilayer sites with heterogeneous energy $[63,64]$. The linear form of Freundlich isotherm model is expressed as:

$$
\ln \mathrm{q}_{\mathrm{eq}}=\ln \mathrm{K}_{\mathrm{f}}+(1 / \mathrm{n}) \ln \mathrm{C}_{\mathrm{eq}}
$$

Equation 7

Where $\mathrm{K}_{\mathrm{f}}(\mathrm{mg} / \mathrm{g})$ is the Freundlich constant correlated with the ion-exchange capacity, and $1 / \mathrm{n}$ (unit less) is the Freundlich constant correlated with the intensity of the reaction and energy heterogeneity [61]. The values of $K_{\mathrm{f}}$ and $1 / \mathrm{n}$ were obtained by plotting $\ln \mathrm{q}_{\mathrm{eq}}$ against $\ln \mathrm{C}_{\mathrm{eq}}$, see Figure 12.

Dubinin-Radushkevitch (D-R) isotherm model can be used to explain both the adsorption on homogenous surfaces and on heterogeneous surfaces $[61,63]$. The linear form of the D-R isotherm is expressed as [28,61]:

$$
\begin{array}{lr}
\ln \mathrm{q}_{\mathrm{eq}}=\ln \mathrm{X}_{\mathrm{m}}-\mathrm{K} \varepsilon^{2} & \text { Equation } 8 \\
\mathcal{E}=\mathrm{RT} \ln \left(1+1 / \mathrm{C}_{\mathrm{eq}}\right) & \text { Equation } 9
\end{array}
$$

Where $\mathrm{X}_{\mathrm{m}}(\mathrm{mg} / \mathrm{g})$ is the maximum ion-exchange capacity, $\mathrm{K}\left(\mathrm{mol}^{2} / \mathrm{kJ}^{2}\right)$ is a constant associated to the ion-exchange energy, $\mathcal{E}(\mathrm{kJ} / \mathrm{mol})$ is the Polanyi potential, $\mathrm{R}(8.314$ $\mathrm{kJ} / \mathrm{kmol} . \mathrm{K})$ is gas law constant and $\mathrm{T}(\mathrm{K})$ is the absolute temperature $[61,65]$. The values of $\mathrm{X}_{\mathrm{m}}$ and $\mathrm{K}$ were calculated by plotting $\ln \mathrm{q}_{\mathrm{eq}}$ against $\varepsilon^{2}$, see Figure 13 . 
The calculated values of Langmuir isotherm constants, Freundlich isotherm constants, D-R isotherm constants and $\mathrm{R}^{2}$ are presented in Table 7. Freundlich isotherm model was best fit to the experimental data. Freundlich isotherm model gave the highest correlation coefficients $\left(\mathrm{R}^{2}\right)$ in comparison with Langmuir and $\mathrm{D}-\mathrm{R}$. This result indicates heterogeneous ion-exchange sites on the surface of ion-exchange materials. The numerical value $1 / \mathrm{n}$ was $<1$ which indicates high heterogeneous surface and high ion-exchange intensity at high ion concentrations.
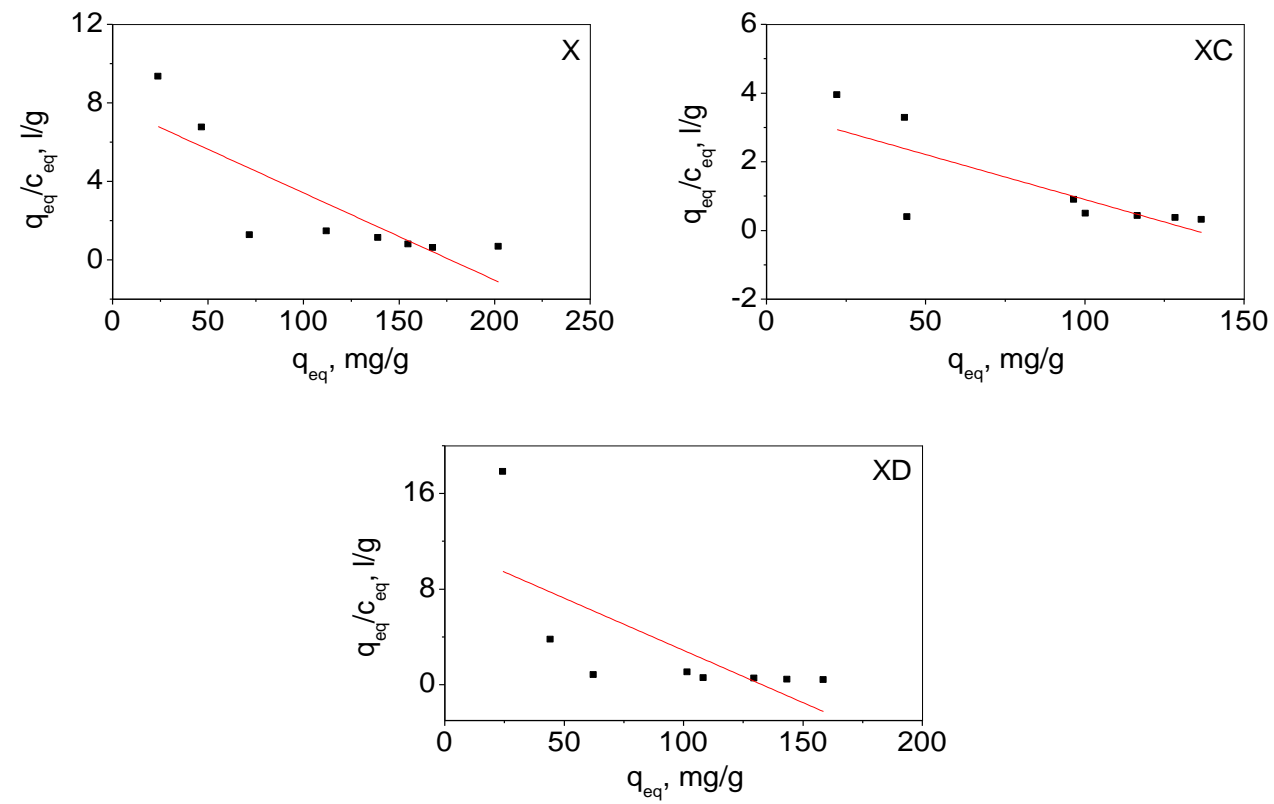

Figure 11: Langmuir plots for ion-exchange of $\mathrm{Mn}^{2+}$ ion showing bad agreement between the experimental data and Langmuir model. 

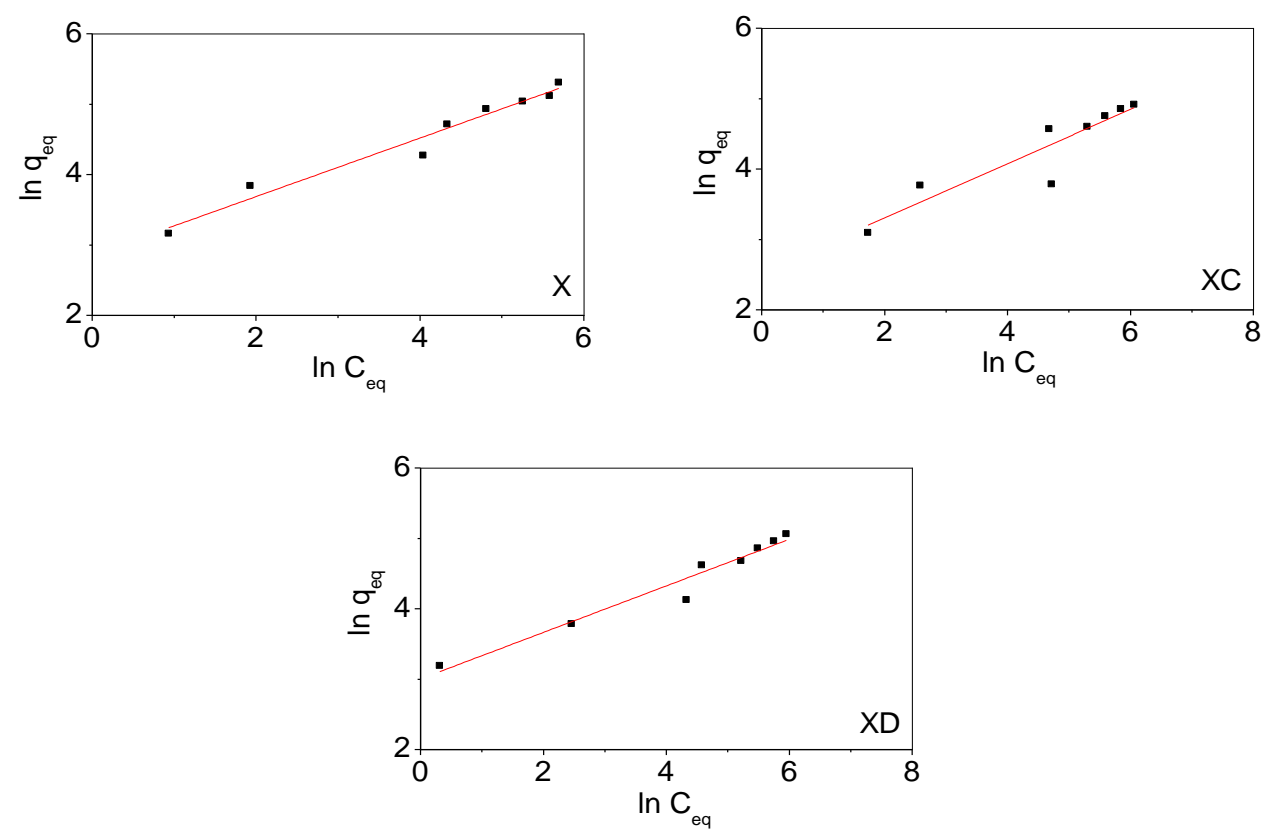

Figure 12: Freundlich plots for ion-exchange of $\mathrm{Mn}^{2+}$ ion showing good agreement between the experimental data and Freundlich model.
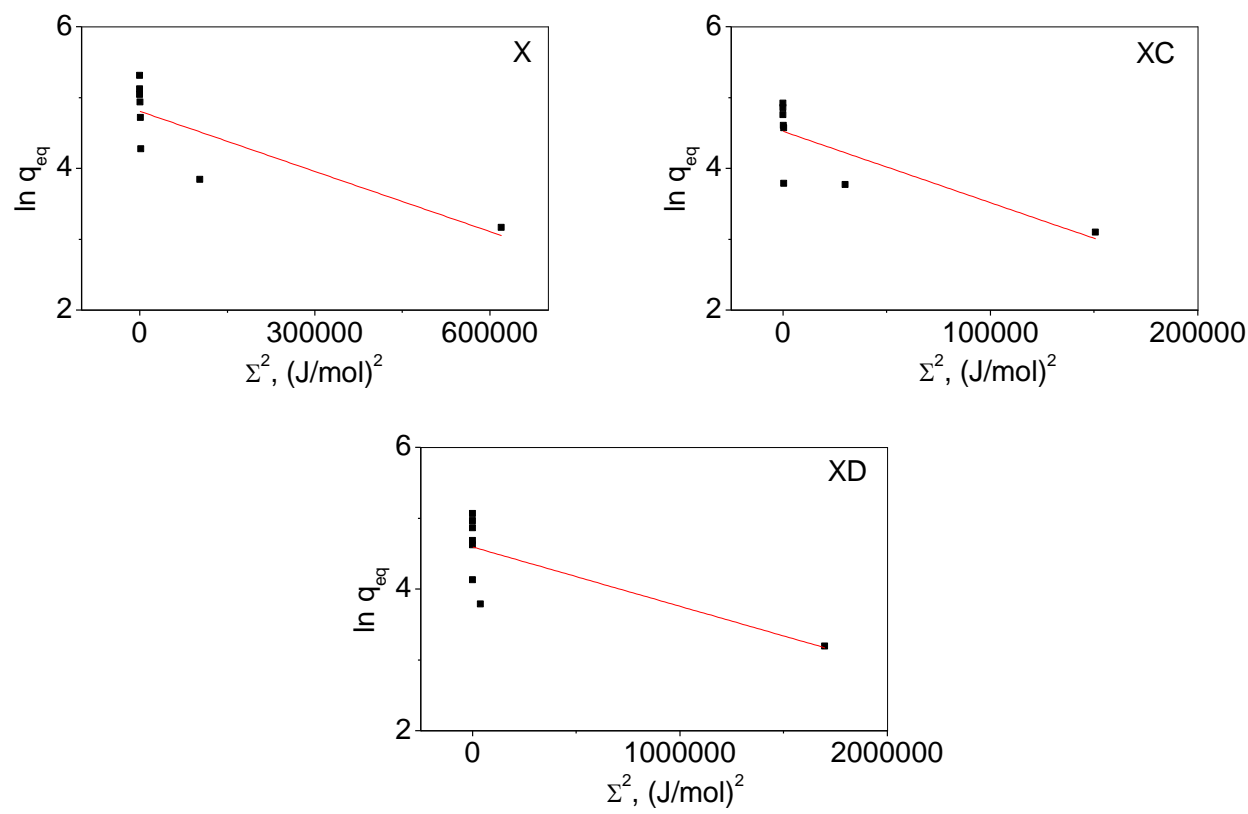

Figure 13: D-R plots for ion-exchange of $\mathrm{Mn}^{2+}$ ion showing bad agreement between the experimental data and D-R model. 
Table 7: The parameters obtained from Langmuir, Freundlich and $\mathrm{D}-\mathrm{R}$ for $\mathrm{Mn}^{2+}$ ion-exchange.

\begin{tabular}{|c|c|c|c|c|c|c|c|c|c|}
\hline \multirow{2}{*}{$\begin{array}{c}\text { Ion-exchanger } \\
\text { material }\end{array}$} & \multicolumn{3}{|c|}{ Langmuir } & \multicolumn{3}{|c|}{ Freundlich } & \multicolumn{3}{|c|}{ D-R } \\
\hline & $\begin{array}{c}\mathbf{q}_{\mathrm{m}} \\
(\mathrm{mg} / \mathrm{g})\end{array}$ & $\begin{array}{c}K_{L} \\
(\mathbf{l} / \mathbf{m g})\end{array}$ & $\mathbf{R}^{2}$ & $\begin{array}{c}\mathbf{K}_{\mathbf{f}} \\
(\mathrm{mg} / \mathrm{g})\end{array}$ & $1 / n$ & $\mathbf{R}^{2}$ & $\begin{array}{c}X_{\mathrm{m}} \\
(\mathrm{mg} / \mathrm{g})\end{array}$ & $\begin{array}{c}\mathrm{K} \\
\left(\mathrm{mol}^{2} / \mathrm{kJ}^{2}\right)\end{array}$ & $\mathbf{R}^{2}$ \\
\hline $\mathbf{X}$ & 177 & 0.0444 & 0.6867 & 17.46 & 0.4155 & 0.9664 & 122.44 & $3 \times 10^{-6}$ & 0.6912 \\
\hline $\mathbf{X C}$ & 134.49 & 0.0262 & 0.788 & 12.67 & 0.3853 & 0.8504 & 92.22 & $1 \times 10^{-5}$ & 0.6466 \\
\hline XD & 133 & 0.0874 & 0.4948 & 20.22 & 0.3305 & 0.9575 & 99.05 & $8 \times 10^{-7}$ & 0.5833 \\
\hline
\end{tabular}

\subsection{Kinetic models of ion-exchange}

Investigating of the rate of ion-exchange is an important to obtain kinetic parameters which are necessary for modelling and design the processes. The ion-exchange kinetics were investigated using pseudo first order and pseudo second order rate models [31,50].

The integrated form of pseudo first order rate equation is given as:

$$
\log \left(\mathrm{q}_{\mathrm{eq}}-\mathrm{q}_{\mathrm{t}}\right)=\log \mathrm{q}_{\mathrm{eq}}-\left(\mathrm{K}_{1} / 2.303\right) \mathrm{t} \quad \text { Equation } 10
$$

Where $\mathrm{q}_{\mathrm{t}}(\mathrm{mg} / \mathrm{g})$ ion-exchange capacity at any time $\mathrm{t}(\mathrm{min})$ and $\mathrm{K}_{1}\left(\mathrm{~min}^{-1}\right)$ is the pseudo first order rate constant of the reaction. The values of $K_{1}$ and $\mathrm{q}_{\mathrm{eq}}$ were calculated by plotting of $\log$ $\left(\mathrm{q}_{\mathrm{eq}}-\mathrm{q}_{\mathrm{t}}\right)$ against $\mathrm{t}[27,66]$.

The pseudo second order model is typically used to correlate the experimental kinetic data when a chemical exchange, which involves valence forces by sharing or electrons exchange between solute and the ion-exchange material, determines the rate of a reaction $[60,67]$. The linear form of integrated pseudo second order kinetic equation is given as:

$$
\mathrm{t} / \mathrm{q}_{\mathrm{t}}=\mathrm{t} / \mathrm{q}_{\mathrm{eq}}+1 / \mathrm{K}_{2}\left(\mathrm{q}_{\mathrm{eq}}\right)^{2}
$$

Where, $\mathrm{K}_{2}$ (g/mg.min) is the pseudo second order model rate constant. The values of $\mathrm{K}_{2}$ and $\mathrm{q}_{\mathrm{eq}}$ were calculated by plotting of $\mathrm{t} / \mathrm{q}_{\mathrm{t}}$ against $\mathrm{t}$. 
Table 8: The parameters obtained from first and second order kinetics models.

\begin{tabular}{|c|c|c|c|}
\hline Ion-exchanger material & $\mathbf{X}$ & $\mathbf{X C}$ & XD \\
\hline \multicolumn{4}{|c|}{ First order kinetics model } \\
\hline$q_{\text {eq(Theoretical) }}(\mathrm{mg} / \mathrm{g})$ & 34.99 & 55.46 & 17.865 \\
\hline $\mathrm{q}_{\text {eq(Experimental })}(\mathrm{mg} / \mathrm{g})$ & 112.01 & 96.514 & 101.448 \\
\hline$K_{1}\left(\min ^{-1}\right)$ & $9.4 \times 10^{-3}$ & $9 \times 10^{-3}$ & $3.9 \times 10^{-3}$ \\
\hline $\mathbf{R}^{2}$ & 0.9857 & 0.9958 & 0.7794 \\
\hline \multicolumn{4}{|c|}{ Second order kinetics model } \\
\hline $\mathrm{q}_{\mathrm{eq}(\text { Theoretical) }}(\mathrm{mg} / \mathrm{g})$ & 114.94 & 103.1 & 103.1 \\
\hline$q_{\text {eq(Experimental) }}(\mathrm{mg} / \mathrm{g})$ & 112.01 & 96.514 & 101.448 \\
\hline$K_{2}$ (g/mg.min) & $9.7 \times 10^{-4}$ & $4.5 \times 10^{-4}$ & $9.8 \times 10^{-4}$ \\
\hline $\mathbf{R}^{2}$ & 1 & 1 & 1 \\
\hline
\end{tabular}

Table 8 shows that the highest values of correlation factor $\left(\mathrm{R}^{2}=1\right)$ were obtained for the pseudo second order model. However, the $\mathrm{R}^{2}$ values obtained for the pseudo first order model were $0.7794-0.9958$. Also, the theoretical values of $\mathrm{q}_{\mathrm{eq}}$ calculated according to pseudo second order model were significantly close to the experimental values ( $\mathrm{q}_{\mathrm{eq} \text { (Experimental) }}$ ). While, $\mathrm{q}_{\mathrm{eq} \text { (Theoretical) }}$ calculated using pseudo first order model were significantly different from $\mathrm{q}_{\mathrm{eq}(\text { Experimental) }}$. These results indicate that the pseudo second order model is more suitable than pseudo first order model to describe the ion-exchange of $\mathrm{Mn}^{2+}$ ion by zeolite $\mathrm{X}$ and its composites. The good match with the second order kinetics model indicates that a chemical reaction related to valence forces could be the rate determining step of the ion exchange process [27].

\subsection{The rate limiting steps}

The rate limiting step for the batch ion-exchange system under homogenous mixing could be one of these steps: film diffusion, intra-particle diffusion, ion-exchange reaction or could be mix of these steps. The Weber and Morris intra-particle diffusion model is used when the rate limiting step is a combination of film diffusion and intra-particle mechanisms $[68,69]$ : 


$$
\mathrm{q}_{\mathrm{t}}=\mathrm{K}_{\mathrm{i}} \mathrm{t}^{1 / 2}+\mathrm{C}
$$

Equation 12

Where $\mathrm{K}_{\mathrm{i}}\left(\mathrm{mg} / \mathrm{g} \cdot \mathrm{min}^{1 / 2}\right)$ is the rate constant of intra-particle diffusion and $\mathrm{C}$ is a constant $(\mathrm{mg} / \mathrm{g})$ related to the thickness of the boundary layer. The large value of $\mathrm{C}$ means more contribution of boundary layer in the rate controlling step $[38,63]$. The values of $\mathrm{K}_{\mathrm{i}}$ and $\mathrm{C}$ were calculated by plotting of $\mathrm{q}_{\mathrm{t}}$ against $\mathrm{t}^{1 / 2}$, see Figure 14 .

In addition, it was assumed that the rate of ion exchange is controlled by the chemical exchange if there is a linear relationship between $\log \left(1-\mathrm{q}_{t} / \mathrm{q}_{\infty}\right)$ and time (Figure 15). $\mathrm{q}_{\infty}$ $(\mathrm{mg} / \mathrm{g})$ is the ion-exchange capacity at equilibrium i.e. qeq (see Figure 15) [60,70,71].

The calculated values of $K_{i}$ and $C$ are shown in Table 9. The plots of $q_{t}$ against $t^{1 / 2}$ for ion-exchange of $\mathrm{Mn}^{2+}$ ion show nonlinear relation contains more than one linear zone with large values of $\mathrm{C}$. The obtained results refer to that the rate determining step of the ionexchange reaction is limited by boundary layer diffusion (which represents the first linear stage of the linear correlation) and the intra-particle diffusion (which represents the second linear stage of the linear correlation). $\mathrm{C}$ value of pure zeolite $\mathrm{X}$ was larger than this for the composites, since it was significantly reduced when composites were used for ion-exchange process. The value of the rate constant of intra-particle diffusion $\left(\mathrm{K}_{\mathrm{i}}\right)$ considerably increased when composites were applied for $\mathrm{Mn}^{2+}$ ion removal. The reason behind this result is that thickness of the external liquid film or the boundary layer decreased when the ion-exchange materials were prepared in form of composite using meso/macroporous supports and the diffusion of ions to the active sites becomes rapid (high $\mathrm{K}_{\mathrm{i}}$ values of composites) which means that the length of diffusion path was reduced.

Moreover, the plots of $\log \left(1-\mathrm{q}_{\mathrm{t}} / \mathrm{q}_{\mathrm{eq}}\right)$ against $\mathrm{t}$ show a linear relation and high values of $\mathrm{R}^{2}$ (0.9681-0.9996). These results refer to that the significant rate determining step is the ion-exchange reaction over zeolite active sites. Thus, the overall ion-exchange rate is 
controlled by a combination of the ion-exchange reaction of $\mathrm{Mn}^{2+}$ ion, the boundary layer diffusion and the intra-particle diffusion, but the utilization of composites in the ion-exchange process makes the effect of the last two steps less effective on the overall rate of ionexchange process.
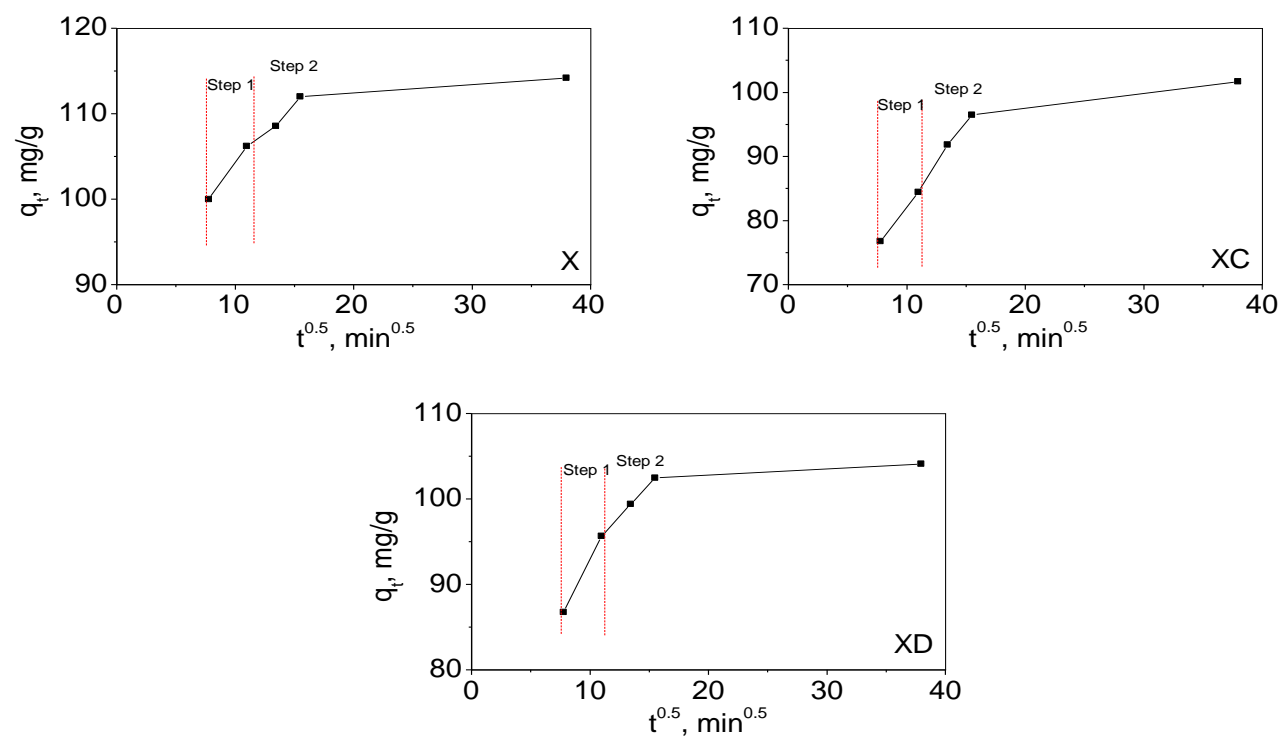

Figure 14: Intra-particle diffusion plots for ion-exchange of $\mathrm{Mn}^{2+}$ ion show step 1 referring to the boundary layer diffusion and step 2 referring to the intra-particle diffusion.
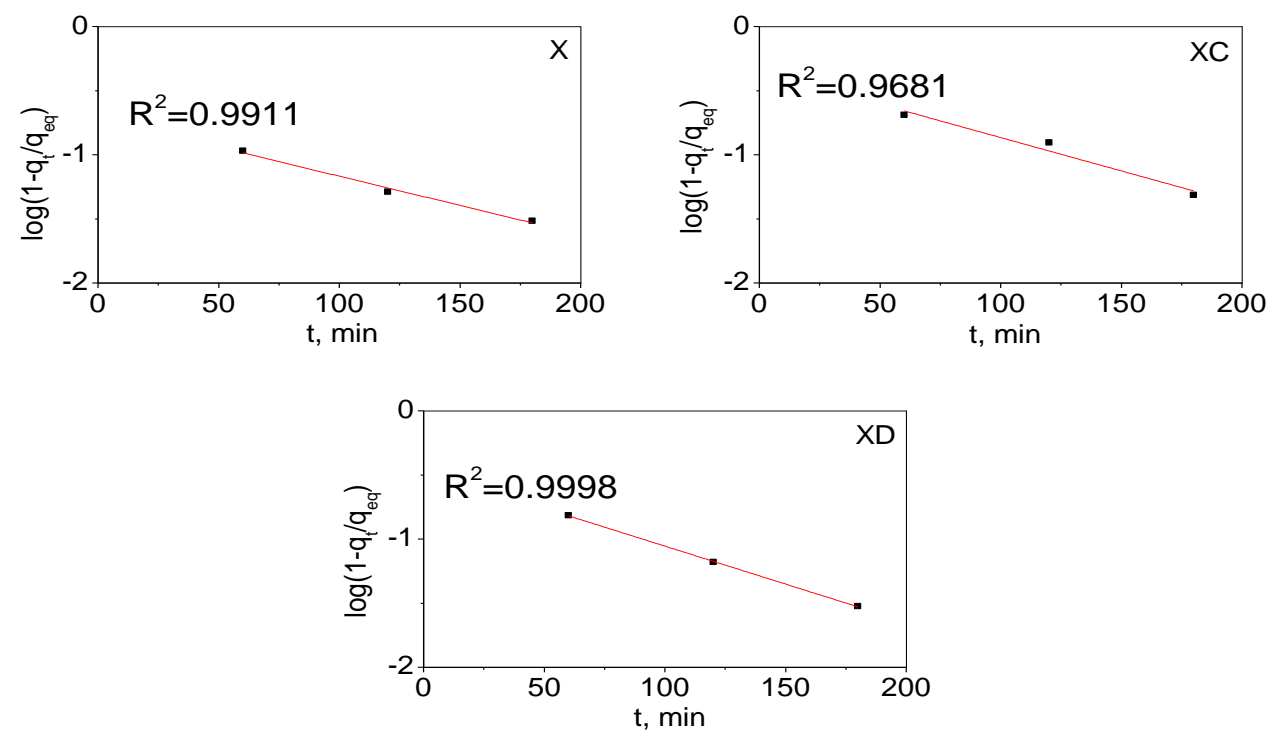

Figure 15: Rate limiting rate plots for ion-exchange of $\mathrm{Mn}^{2+}$ ion. 
Table 9: Intra-particle diffusion model parameters obtained for $\mathrm{Mn}^{2+}$ ion-exchange.

\begin{tabular}{|c|c|c|c|}
\hline Ion-exchanger material & $\mathbf{X}$ & $\mathrm{XC}$ & XD \\
\hline$K_{i}\left(m g / g \cdot m^{1 / 2}\right)$ & 1.5065 & 2.5882 & 2.0124 \\
\hline $\mathrm{C}(\mathrm{mg} / \mathrm{g})$ & 88.773 & 56.594 & 72.126 \\
\hline $\mathbf{R}^{2}$ & 0.9835 & 0.9976 & 0.9713 \\
\hline
\end{tabular}

\subsection{Solidification of the spent zeolite}

\subsubsection{Vitrification}

Figure 16 shows samples of zeolite ion-exchange materials used for manganese removal before and after vitrification process. The powder samples converted to hard glass products with a brown pigment because of a reaction happened between aluminate and manganese ions at elevated temperature.
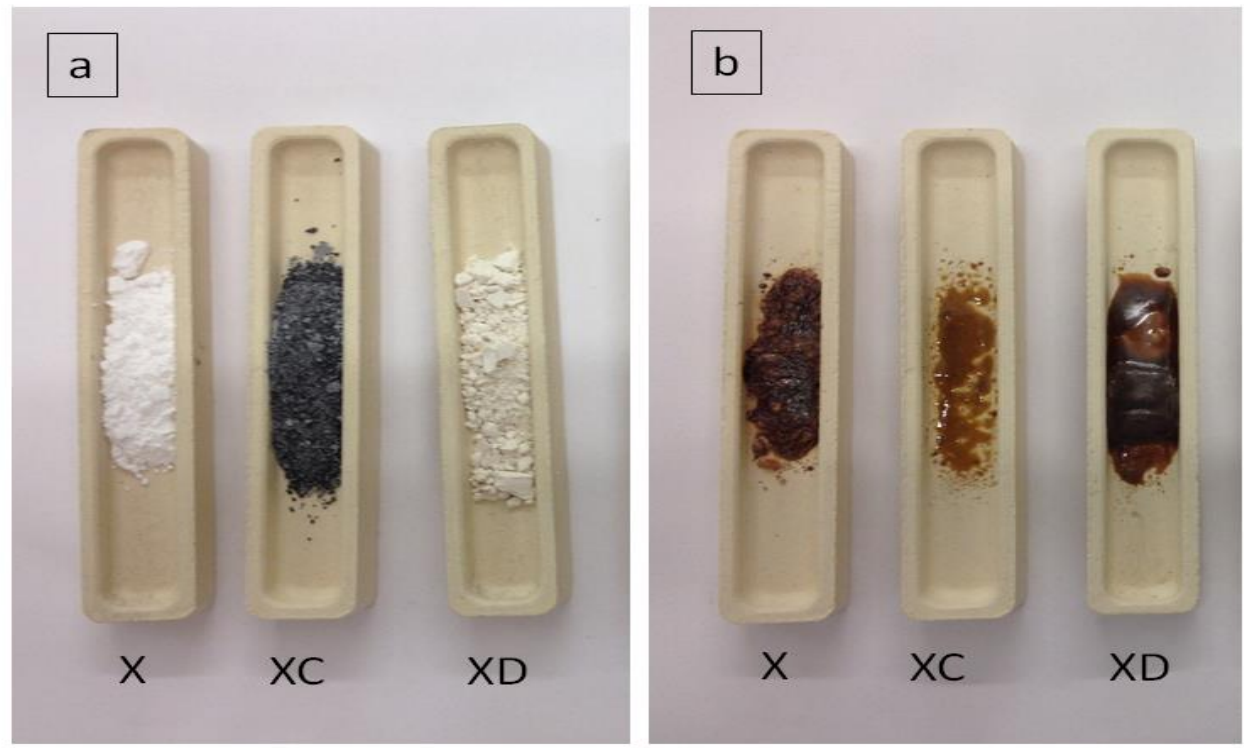

Figure 16: Zeolite ion-exchange materials after ion-exchange with manganese ion (a) before and (b) after vitrification at $1200^{\circ} \mathrm{C}$.

The characterization was focused on the solution because the major concern of this work is elimination the leaching of metal ions to the environment. The samples resulted from vitrification process were examined for leaching of manganese ion by immersing in water 
and $\mathrm{NaCl}$ solution and the results are shown in Table 10. The results showed releasing manganese ions with insignificant concentrations $\sim 0.4 \mathrm{ppm}$. The samples of ion-exchange materials before vitrification released higher concentration of manganese ion and the concentration increased with time. Non-vitrified samples released more manganese ion when immersed in $\mathrm{NaOH}$ solution. Therefore, direct disposal of the ion-exchange materials used for harmful elements to the environment without treatment allows continual escaping the harmful ions to the environment. Vitrification process immobilizes the harmful ions and stops ions releasing to the environment. Also, it diminishes the size of waste sludge. Table 11 shows the weight of ion-exchange materials after vitrification process was significantly reduced. Especially, when zeolite/carbon composite was vitrified, its weight becomes significantly smaller than pure zeolite and zeolite/diatomite composite. This is because the carbon involved in the composites turns to $\mathrm{CO}_{2}$. Thus, it can be said that zeolite/carbon composites enhance the mass transfer and the ion-exchange performance, reduce the weight of zeolite required for a given process and consequently diminish the waste size when are vitrified. When zeolite/diatomite composites are vitrified, they produce larger volume products than zeolite/carbon composites produce; because diatomite skeleton is formed of silica and it does not convert to gas when it is heated at elevated temperatures.

Table 10: Concentration of $\mathrm{Mn}^{2+}$ ion leached to water and $0.1 \mathrm{M} \mathrm{NaCl}$ solution before and after encapsulation with vitrification.

\begin{tabular}{|c|c|c|c|c|}
\hline \multirow{2}{*}{ Materials } & \multicolumn{2}{|c|}{$\begin{array}{c}\text { Concentration of } \mathbf{M n}^{2+} \text { ion leached to } \\
\text { the solutions }(\mathbf{p p m}) \text { after one month }\end{array}$} & $\begin{array}{c}\text { Concentration of } \mathbf{M n}^{\mathbf{2 +}} \text { ion leached to } \\
\text { the solutions (ppm) after six months }\end{array}$ \\
\cline { 2 - 5 } & $\mathrm{H}_{2} \mathrm{O}$ & $0.1 \mathrm{M} \mathrm{NaCl}$ solution & $\mathrm{H}_{2} \mathrm{O}$ & $0.1 \mathrm{M} \mathrm{NaCl} \mathrm{solution}$ \\
\hline $\begin{array}{c}\text { Spent ion-exchangers } \\
\text { before any treatment }\end{array}$ & $0.068-1.76$ & $7.796-116.5$ & $0.64-1.76$ & $9.14-88.363$ \\
\hline Vitrified samples & $0-0.13$ & $0-0.335$ & $0-0.26$ & $0-0.418$ \\
\hline
\end{tabular}


Table 11: Weight of the vitrified spent zeolitic material per $1 \mathrm{~g}$ of the material before vitrification process.

\begin{tabular}{|c|c|c|c|}
\hline Materials & Zeolite X & $\begin{array}{c}\text { Zeolite } \\
\text { X/carbon }\end{array}$ & $\begin{array}{c}\text { Zeolite } \\
\text { X/diatomite }\end{array}$ \\
\hline $\begin{array}{c}\text { Weight of the vitrified material (g) per 1 g of the } \\
\text { material before vitrification }\end{array}$ & 0.736 & 0.275 & 0.789 \\
\hline
\end{tabular}

\subsubsection{Geopolymerization}

Figure 17 shows samples of spent ion-exchange materials solidified by geopolymers. The concentrations of $\mathrm{Mn}^{2+}$ ion escaped from the solidified materials are shown in Table 12 . There detected concentrations of manganese ion leached to water and $\mathrm{NaCl}$ solution are negligible. But, the concentrations of manganese ion leached from geopolymers to $\mathrm{H}_{2} \mathrm{SO}_{4}$ solution were $<5 \mathrm{ppm}$ after six months. Therefore, geopolymerization technique allows less energy used for successful immobilization of the harmful ions in spite of it converts the waste material into larger volume product.

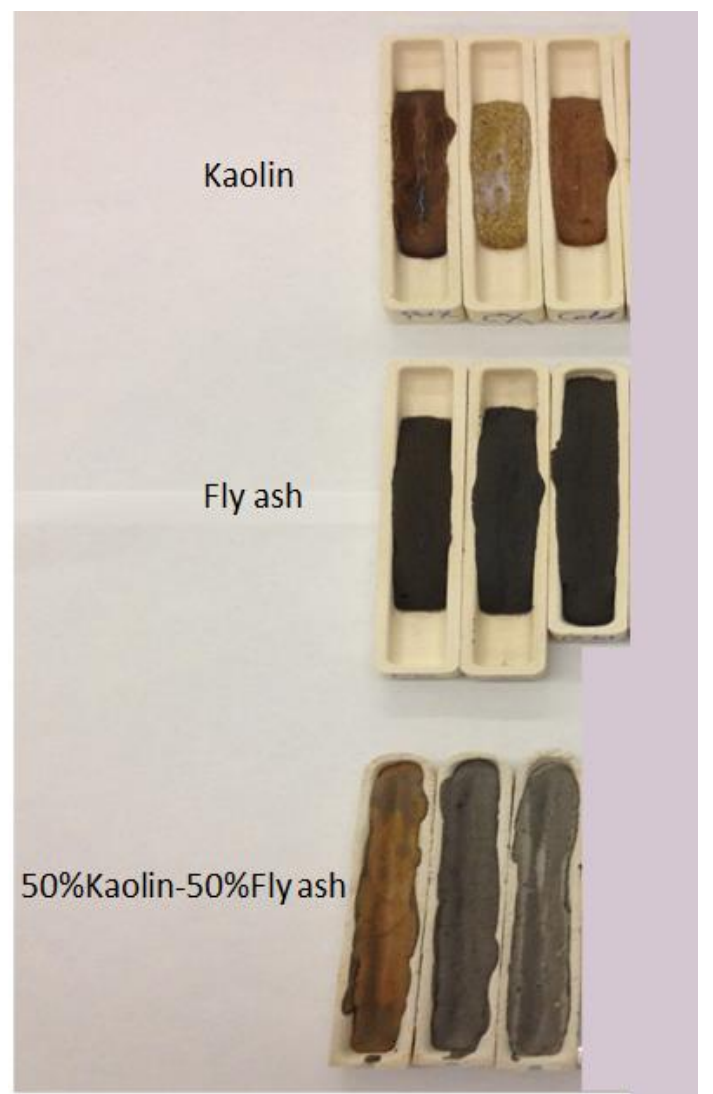

Figure 17: Zeolite ion-exchange materials after ion-exchange with manganese ion treated with geopolymers made of kaolin, fly ash and 50\% kaolin - 50\% fly ash. The samples from left to right are: X, XC and XD. 
Table 12: Concentration of $\mathrm{Mn}^{2+}$ ions leached to water, $0.1 \mathrm{M} \mathrm{NaCl}$ solution and $0.25 \mathrm{M} \mathrm{H}_{2} \mathrm{SO}_{4}$ from samples encapsulated with geopolymers.

\begin{tabular}{|c|c|c|c|c|c|c|}
\hline \multirow[t]{2}{*}{ Materials } & \multicolumn{3}{|c|}{$\begin{array}{c}\text { Concentration of } \mathrm{Mn}^{2+} \text { ions leached } \\
\text { to the solutions }(\mathrm{ppm}) \text { after one } \\
\text { month }\end{array}$} & \multicolumn{3}{|c|}{$\begin{array}{c}\text { Concentration of } \mathrm{Mn}^{2+} \text { ions leached } \\
\text { to the solutions }(\mathrm{ppm}) \text { after six } \\
\text { months }\end{array}$} \\
\hline & $\mathrm{H}_{2} \mathrm{O}$ & $\begin{array}{c}0.1 \mathrm{M} \mathrm{NaCl} \\
\text { solution }\end{array}$ & $\begin{array}{l}0.25 \mathrm{M} \\
\mathrm{H}_{2} \mathrm{SO}_{4} \\
\text { solution }\end{array}$ & $\mathrm{H}_{2} \mathrm{O}$ & $\begin{array}{c}0.1 \mathrm{M} \mathrm{NaCl} \\
\text { solution }\end{array}$ & $\begin{array}{l}0.25 \mathrm{M} \\
\mathrm{H}_{2} \mathrm{SO}_{4} \\
\text { solution }\end{array}$ \\
\hline $\begin{array}{l}\text { Samples encapsulated } \\
\text { with kaolin geopolymer }\end{array}$ & $0-0.11$ & $0.02-0.16$ & $1.64-2.266$ & $\begin{array}{c}0.05- \\
0.1\end{array}$ & $0-0.06$ & $2.67-3.11$ \\
\hline $\begin{array}{l}\text { Samples encapsulated } \\
\text { with fly ash geopolymer }\end{array}$ & $\begin{array}{l}0.03- \\
0.08\end{array}$ & $0.07-0.45$ & $1.64-2.26$ & $0-0.03$ & $0-0.03$ & $2.18-3.25$ \\
\hline $\begin{array}{c}\text { Samples encapsulated } \\
\text { with } 50 \% \text { kaolin - 50\% } \\
\text { fly ash geopolymer }\end{array}$ & $\begin{array}{l}0.05- \\
0.61\end{array}$ & $0.1-0.27$ & $2.65-3.88$ & $0-0.24$ & $0.05-0.19$ & $3.68-4.867$ \\
\hline
\end{tabular}

\section{Conclusion}

In the present work, the zeolite $\mathrm{X} /$ carbon composite and zeolite $\mathrm{X} /$ diatomite composite were successfully prepared by a hydrothermal treatment. Zeolite X layer coating porous supports showed perfect attachment even when the composites were used in the ion-exchange process for $\mathrm{Mn}^{2+}$ ion removal. All X, XC and XD showed interesting ability for manganese removal. The performance of ion-exchange materials for ion-exchange process showed the following order: $\mathrm{XD}>\mathrm{XC}>\mathrm{X}$ when the ion-exchange capacity was calculated based on the weight of zeolite present in the composites. $\mathrm{Mn}^{2+}$ ion removal was affected by initial ion concentration, temperature and $\mathrm{pH}$ of manganese solution. A study of thermodynamic parameters displayed that the ion-exchange reaction of $\mathrm{Mn}^{2+}$ ions is a spontaneous and endothermic. For all ionexchange materials, the Freundlich isotherm model successfully agreed with the experimental data of $\mathrm{Mn}^{2+}$ ion removal by the ion-exchange process. The kinetic study of the ion-exchange process indicated that the pseudo second order model significantly described the experimental data. The overall ion-exchange process of $\mathrm{Mn}^{2+}$ ions is determined by a combination of ion-exchange reaction and less of both boundary layer film and intra-particle 
diffusion. Appling of composites in the ion-exchange process reduced the effect of boundary layer film and intra-particle diffusion on the overall rate of ion-exchange reaction. Encapsulation of $\mathrm{Mn}^{2+}$ ion was successfully conducted by vitrification at $1200^{\circ} \mathrm{C}$ and geopolymerization. Vitrification process resulted in smaller volume solid product than geopolymerization in spite of vitrification requires more energy than required for geopolymerization.

\section{Acknowledgement}

The authors would like to thank Patrick Hill for his support and the Higher Committee for Education Development in Iraq and University of Baghdad for supporting Sama M. Aljubouri.

\section{References}

[1] M. Razavian and S. Fatemi, Synthesis and evaluation of seed-directed hierarchical ZSM-5 catalytic supports : Inductive influence of various seeds and aluminosilicate gels on the physicochemical properties and catalytic dehydrogenative behavior, Mater. Chem. Phys. 165 (2015) 55-65.

[2] S. Narayanan, J.J. Vijaya, S. Sivasanker, L.J. Kennedy and S.K. Jesudoss, Structural, morphological and catalytic investigations on hierarchical ZSM-5 zeolite hexagonal cubes by surfactant assisted hydrothermal method, Powder Technol. 274 (2015) 338-348.

[3] D. Verboekend, T.C. Keller, S. Mitchell and J. Pérez-Ramírez, Hierarchical FAU- and LTA-type zeolites by post-synthetic design: A new generation of highly efficient base catalysts, Adv. Funct. Mater. 23 (2013) 1923-1934. 
[4] X. Yin, Z. Li, S. Wang, N. Chu, J. Yang and J. Wang, Hydrothermal synthesis of hierarchical zeolite $\mathrm{T}$ aggregates using tetramethylammonium hydroxide as single template, Microporous Mesoporous Mater. 201 (2015) 247-257.

[5] Z. L. Hua, J. Zhou and J.L. Shi, Recent advances in hierarchically structured zeolites: synthesis and material performances, Chem. Commun. 47 (2011) 10536-10547.

[6] S. van Donk, A.H. Janssen, J.H. Bitter and K.P. de Jong, Generation, characterization, and impact of mesopores in zeolite catalysts, Catal. Rev. 45 (2003) 297-319.

[7] X. Meng, F. Nawaz and F.-S. Xiao, Templating route for synthesizing mesoporous zeolites with improved catalytic properties, Nano Today 4 (2009) 292-301.

[8] L. Ding and Y. Zheng, Effect of template concentration and gel dilution on crystallization and particle size of zeolite beta in the absence of alkali cations, Microporous Mesoporous Mater. 103 (2007) 94-101.

[9] W. Yu, L. Deng, P. Yuan, D. Liu, W. Yuan and F. Chen, Preparation of hierarchically porous diatomite/MFI-type zeolite composites and their performance for benzene adsorption: The effects of desilication, Chem. Eng. J. 270 (2015) 450-458.

[10] J. Ahmadpour and M. Taghizadeh, Catalytic conversion of methanol to propylene over high-silica mesoporous ZSM-5 zeolites prepared by different combinations of mesogenous templates, J. Nat. Gas Sci. Eng. 23 (2015) 184-194.

[11] J. Zhao, Y. Yin, Y. Li, W. Chen and B. Liu, Synthesis and characterization of mesoporous zeolite Y by using block copolymers as templates, Chem. Eng. J. 284 (2016) pp. 405-411. 
[12] X. Dong, C.F. Zhou, M.B. Yue, C.Z. Zhang, W. Huang and J.H. Zhu, New application of hierarchical zeolite in life science: Fast trapping nitrosamines in artificial gastric juice by alkaline-tailored HZSM-5, Mater. Lett. 61 (2007) 3154-3158.

[13] O. Hernández-Ramirez, S.K. Al-Nasri and S.M. Holmes, Hierarchical structures based on natural carbons and zeolites, J. Mater. Chem. 21 (2011) 16529-16534.

[14] O. Hernández-Ramírez, P.I. Hill, D.J. Doocey and S.M. Holmes, Removal and immobilisation of cobalt ions by a novel, hierarchically structured, diatomite/zeolite Y composite, J. Mater. Chem. 17 (2007) 1804-1808.

[15] W. Yuan, P. Yuan, D. Liu, W. Yu, M. Laipan, L. Deng and F. Chen, In situ hydrothermal synthesis of a novel hierarchically porous TS-1/modified-diatomite composite for methylene blue (MB) removal by the synergistic effect of adsorption and photocatalysis, J. Colloid Interface Sci. 462 (2016) 191-199.

[16] X. Cai, G. Zhu, W. Zhang, H. Zhao, C. Wang, S. Qiu and Y. Wei, Diatom-Templated Synthesis of Ordered Meso/Macroporous Hierarchical Materials, Eur. J. Inorg. Chem. (2006) $3641-3645$.

[17] Y.J. Wang, Y. Tang, X.D. Wang, A.G. Dong, W. Shan and Z. Gao, Fabrication of hierarchically structured zeolites through layer-by-layer assembly of zeolite nanocrystals on diatom templates, Chem. Lett. 30 (2001) 1118-1119.

[18] Y. Wang, Y. Tang, A. Dong, X. Wang, N. Ren and Z. Gao, Zeolitization of diatomite to prepare hierarchical porous zeolite materials through a vapor-phase transport process, J. Mater. Chem. 12 (2002) 1812-1818. 
[19] D.A. De Haro-Del Rio, S. Al-Jubouri, O. Kontogiannis, D. Papadatos-Gigantes, O. Ajayi, C. Li and S.M. Holmes, The removal of caesium ions using supported clinoptilolite, J. Hazard. Mater. 289 (2015) 1-8.

[20] L. Shan, J. Shao, Z. Wang and Y. Yan, Preparation of zeolite MFI membranes on alumina hollow fibers with high flux for pervaporation, J. Memb. Sci. 378 (2011) 319-329.

[21] G. Xomeritakis, S. Nair and M. Tsapatsis, Transport properties of alumina-supported MFI membranes made by secondary (seeded) growth, Microporous Mesoporous Mater. 38 (2000) 61-73.

[22] X. Zou, G. Zhu, H. Guo, X. Jing, D. Xu and S. Qiu, Effective heavy metal removal through porous stainless-steel-net supported low siliceous zeolite ZSM-5 membrane, Microporous Mesoporous Mater. 124 (2009) 70-75.

[23] X. Yin, G. Zhu, W. Yang, Y. Li, G. Zhu, R. Xu, J. Sun, S. Qiu and R. Xu, Stainlesssteel-net-supported zeolite $\mathrm{NaA}$ membrane with high permeance and high permselectivity of oxygen over nitrogen, Adv. Mater. 17 (2005) 2006-2010.

[24] H. Wang, B.A. Holmberg and Y. Yan, Homogeneous polymer-zeolite nanocomposite membranes by incorporating dispersible template-removed zeolite nanocrystals, J. Mater. Chem. 12 (2002) 3640-3643.

[25] S.K. Al-Nasri and S.M. Holmes, Effect of different conditions on the sorption behavior of $\mathrm{Co}^{2+}$ using celatom- zeolite Y composite, 7 (2013) 311-317.

[26] S. Wang and Y. Peng, Natural zeolites as effective adsorbents in water and wastewater treatment, Chem. Eng. J. 156 (2010) 11-24. 
onto $\mathrm{NaA}$ and $\mathrm{NaX}$ zeolites: kinetic, equilibrium and thermodynamic studies, J. Hazard. Mater. 173 (2010) 637-646.

[28] A. Nilchi, R. Saberi, M. Moradi, H. Azizpour and R. Zarghami, Adsorption of cesium on copper hexacyanoferrate-PAN composite ion exchanger from aqueous solution, Chem. Eng. J. 172 (2011) 572-580.

[29] E.S. Dragan, M.V. Dinu and D. Timpu, Preparation and characterization of novel composites based on chitosan and clinoptilolite with enhanced adsorption properties for $\mathrm{Cu}^{2+}$, Bioresour. Technol. 101 (2010) 812-817.

[30] A.A. Mengistie, T.S. Rao and A.V. Prasada Rao, Adsorption of Mn(II) ions from wastewater using activated carbon obtained from birbira (militia ferruginea) leaves, Glob. J. Sci. Front. Res. Chem. 12 (2012) 5-11.

[31] M. Ghaedi, S. Hajati, F. Karimi, B. Barazesh and G. Ghezelbash, Equilibrium, kinetic and isotherm of some metal ion biosorption, J. Ind. Eng. Chem. 19 (2013) 987-992.

[32] International Manganese Institute, Manganese in Groundwater: Research and potential risks, Int. Manganese Inst. (2013) 1-2.

[33] M.P. Tavlieva, S.D. Genieva, V.G. Georgieva and L.T. Vlaev, Thermodynamics and kinetics of the removal of manganese(II) ions from aqueous solutions by white rice husk ash, J. Mol. Liq. 211 (2015) 938-947.

[34] Water quality fact sheet : manganese, British Geological Survey, 2003.

[35] M. Ahmaruzzaman, Industrial wastes as low-cost potential adsorbents for the treatment of wastewater laden with heavy metals, Adv. Colloid Interface Sci. 166 (2011) 36-59. 
[36] Magnesium-Mg, Chemical properties of magnesium-health effects of magnesiumenvironmental effects of magnesium, [http://www.lenntech.com/ periodic/elements/mg.htm], Access date: 17-08-2014.

[37] M. Ajmal, R. A. Khan Rao, S. Anwar, J. Ahmad and R. Ahmad, Adsorption studies on rice husk: removal and recovery of Cd(II) from wastewater, Bioresour. Technol. 86 (2003) $147-149$.

[38] P. SenthilKumar, S. Ramalingam, V. Sathyaselvabala, S.D. Kirupha and S. Sivanesan, Removal of copper(II) ions from aqueous solution by adsorption using cashew nut shell, Desalination 266 (2011) 63-71.

[39] Y.-J. Du, S.-Y. Liu, Z.-B. Liu, L. Chen, F. Zhang and F. Jin, An overview of stabilization/ solidification technique for heavy metals contaminated soils, Proc. of Int. Symp. on Geoenvironmental Eng (2009) 760-766.

[40] E. Bernardo, M. Varrasso, F. Cadamuro and S. Hreglich, Vitrification of wastes and preparation of chemically stable sintered glass-ceramic products, J. Non. Cryst. Solids 352 (2006) 4017-4023.

[41] O. Pinet, J.L. Dussossoy, C. David and C. Fillet, Glass matrices for immobilizing nuclear waste containing molybdenum and phosphorus, J. Nucl. Mater. 377 (2008) 307-312.

[42] H. Wang, H. Li and F. Yan, Synthesis and mechanical properties of metakaolinitebased geopolymer, Colloids Surfaces A Physicochem. Eng. Asp. 268 (2005) 1-6.

[43] Z. Zuhua, Y. Xiao, Z. Huajun and C. Yue, Role of water in the synthesis of calcined kaolin-based geopolymer, Appl. Clay Sci. 43 (2009) 218-223. 
[44] A.M.M. Al Bakri, M.T.M. Faheem, A.V. Sandu, A. Alida, M.A.A. Salleh and C.M. Ruzaidi, Microstructure studies on different types of Geopolymer materials, Applied Mechanics and Materials, 421 (2013) 384-389.

[45] M. Iwama, Y. Suzuki, J. Plévert, K. Itabashi, M. Ogura and T. Okubo, Location of alkali ions and their relevance to crystallization of low silica X zeolite, Cryst. Growth Des. 10 (2010) 3471-3479.

[46] K.E. Hamilton, E.N. Coker, A. Sacco Jr, A.G. Dixon and R.W. Thompson, The effects of the silica source on the crystallization of zeolite NaX, Zeolites 13 (1993) 645-653.

[47] P.A. Howell and N.Y. Grand Island, Process for producing molecular sieves, US Patent No. 3101251, 1963.

[48] H. Xu and J.S.J. Van Deventer, The geopolymerisation of alumino-silicate minerals, Int. J. Miner. Process. 59 (2000) 247-266.

[49] J.G.S. Van Jaarsveld, J.S.J. Van Deventer and L. Lorenzen, Factors affecting the immobilization of metals in geopolymerized flyash, Metall. Mater. Trans. B 29 (1998) 283291.

[50] A.M. El-Kamash, A.A. Zaki and M.A. El Geleel, Modeling batch kinetics and thermodynamics of zinc and cadmium ions removal from waste solutions using synthetic zeolite A, J. Hazard. Mater. B 127 (2005) 211-20.

[51] H. van Bekkum, E.M. Flanigen and J.C. Jansen, Introduction to zeolite science and practice, Studies in Surface Science and Catalysis 137, Elsevier Science B.V, Delft, 2001.

[52] M. Ghasemi, H. Javadian, N. Ghasemi, S. Agarwal and V.K. Gupta, Microporous nanocrystalline $\mathrm{NaA}$ zeolite prepared by microwave assisted hydrothermal method and 
determination of kinetic, isotherm and thermodynamic parameters of the batch sorption of $\mathrm{Ni}$ (II), J. Mol. Liq. 215 (2016) 161-169.

[53] H. Tang, W. Zhou and L. Zhang, Adsorption isotherms and kinetics studies of malachite green on chitin hydrogels, J. Hazard. Mater. 209-210 (2012) 218-225.

[54] D. Ding, Y. Zhao, S. Yang, W. Shi, Z. Zhang, Z. Lei and Y. Yang, Adsorption of cesium from aqueous solution using agricultural residue-walnut shell: equilibrium, kinetic and thermodynamic modeling studies, Water Res. 47 (2013) 2563-2571.

[55] O. Ilgen and H.S. Dulger, Removal of oleic acid from sunflower oil on zeolite 13X: Kinetics, equilibrium and thermodynamic studies, Ind. Crops Prod. 81 (2016) 66-71.

[56] M. Deravanesiyan, M. Beheshti and A. Malekpour, The removal of $\mathrm{Cr}(\mathrm{III})$ and $\mathrm{Co}(\mathrm{II})$ ions from aqueous solution by two mechanisms using a new sorbent (alumina nanoparticles immobilized zeolite)_Equilibrium, kinetic and thermodynamic studies, J. Mol. Liq. 209 (2015) 246-257.

[57] A. Abdolali, H.H. Ngo, W. Guo, S. Lu, S.-S. Chen, N.C. Nguyen, X. Zhang, J. Wang and $\mathrm{Y}$. Wu, A breakthrough biosorbent in removing heavy metals: Equilibrium, kinetic, thermodynamic and mechanism analyses in a lab-scale study, Sci. Total Environ. 542 (2016) $603-611$.

[58] H.S. Ibrahim, T.S. Jamil and E.Z. Hegazy, Application of zeolite prepared from Egyptian kaolin for the removal of heavy metals: II. Isotherm models, J. Hazard. Mater. 182 (2010) 842-847.

[59] W.S.W. Ngah and S. Fatinathan, Adsorption characterization of $\mathrm{Pb}$ (II) and $\mathrm{Cu}$ (II) ions onto chitosan-tripolyphosphate beads: Kinetic, equilibrium and thermodynamic studies, J. Environ. Manage. 91 (2010) 958-969. 
[60] D. Karadag, Y. Koc, M. Turan and M. Ozturk, A comparative study of linear and nonlinear regression analysis for ammonium exchange by clinoptilolite zeolite, J. Hazard. Mater. 144 (2007) 432-437.

[61] M.E. Argun, Use of clinoptilolite for the removal of nickel ions from water: Kinetics and thermodynamics, J. Hazard. Mater. 150 (2008) 587-595.

[62] I.C. Ostroski, M.A.S.D. Barros, E.A. Silva, J.H. Dantas, P.A. Arroyo and O. Lima, A comparative study for the ion exchange of Fe (III) and $\mathrm{Zn}$ (II) on zeolite NaY, J. Hazard. Mater. 161 (2009) 1404-1412.

[63] H. Chen, J. Zhao, J. Wu and G. Dai, Isotherm, thermodynamic, kinetics and adsorption mechanism studies of methyl orange by surfactant modified silkworm exuviae, J. Hazard. Mater. 192 (2011) 246-254.

[64] M.S. Al-Harahsheh, K. Al Zboon, L. Al-Makhadmeh, M. Hararah and M. Mahasneh, Fly ash based geopolymer for heavy metal removal: A case study on copper removal, J. Environ. Chem. Eng. 3 (2015) 1669-1677.

[65] M. Soleimani and Z.H. Siahpoosh, Ghezeljeh nanoclay as a new natural adsorbent for the removal of copper and mercury ions: Equilibrium, kinetics and thermodynamics studies, Chinese J. Chem. Eng. 23 (2015) 1819-1833.

[66] U. Maheshwari, B. Mathesan and S. Gupta, Efficient adsorbent for simultaneous removal of $\mathrm{Cu}(\mathrm{II}), \mathrm{Zn}(\mathrm{II})$ and $\mathrm{Cr}(\mathrm{VI})$ : Kinetic, thermodynamics and mass transfer mechanism, Process Saf. Environ. Prot. 98 (2015) 198-210.

[67] K.S. Hui, C.Y.H. Chao and S.C. Kot, Removal of mixed heavy metal ions in wastewater by zeolite 4A and residual products from recycled coal fly ash, J. Hazard. Mater. B 127 (2005) 89-101. 
[68] H. Wang, X. Yuan, Y. Wu, H. Huang, G. Zeng, Y. Liu, X. Wang, N. Lin and Y.Qi, Adsorption characteristics and behaviors of graphene oxide for $\mathrm{Zn}(\mathrm{II})$ removal from aqueous solution, Appl. Surf. Sci. 279 (2013) 432-440.

[69] A. Adamczuk and D. Kołodyńska, Equilibrium, thermodynamic and kinetic studies on removal of chromium, copper, zinc and arsenic from aqueous solutions onto fly ash coated by chitosan, Chem. Eng. J. 274 (2015) 200-212.

[70] R. Turse and W. Riemak, Kinetics of ion exchange in a chelatixg resin, 65 (1961) $1821-1824$.

[71] A. Varon and W. Rieman, Kinetics of ion exchange in a chelatixg resin, J. Phys. Chem. 68 (1964) 2716-2718. 